\title{
Public health competencies for pharmacists: A scoping review
}

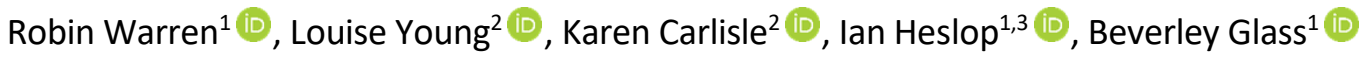 \\ 1Pharmacy, College of Medicine and Dentistry, James Cook University, Australia \\ ${ }^{2}$ Medicine, College of Medicine and Dentistry, James Cook University, Australia \\ ${ }^{3}$ College of Science, University of Lincoln, Lincolnshire, United Kingdom
}

\section{Keywords \\ Competence \\ Global health \\ Pharmacy \\ Public health}

\section{Correspondence}

Robin Warren

College of Medicine and Dentistry

James Cook University

Australia

robin.warren@jcu.edu.au

\begin{abstract}
Background: Pharmacists are increasingly called to integrate population health approaches into their role. Public health knowledge and skills are recommended to be incorporated into the pharmacy curricula and professional development to enable competence of pharmacists in this area. Aim: To describe the competencies required by pharmacists to contribute to the public health of populations. Methods: A scoping review of peer-reviewed and grey literature discussing competencies in both pharmacy and public health was conducted. Competencies were extracted into a matrix of pharmacy and public health competencies and inductive coding of themes was undertaken. Results: Analysis of 58 papers showed important themes of professionalism, communication and collaboration with communities and other health professionals. Pharmacist services providing health promotion, screening and disease prevention should be directed at community needs. Evolution of pharmacy competencies in global health, health informatics and disaster management are current topics. Conclusion: $A$ public health perspective in all pharmacy competency domains may assist pharmacists to understand their responsibility in improving the health and wellbeing of communities and ensure the profession has a positive impact on local, national and global health indicators.
\end{abstract}

\section{Introduction}

The health needs of the world's population are changing rapidly, with health professionals facing new challenges and opportunities (Frenk et al., 2010). Population health demands as well as changes in technology, environmental threats and globalisation contribute to the necessity for change in the roles, education and competency of health professionals (Frenk et al., 2010; Fleming \& Parker, 2015). In conjunction with the provision of individualised patient-centred care, health professionals are increasingly required to incorporate public health approaches and interventions to improve the health status of communities or populations (Frenk et al., 2010; Zenzano et al., 2011). The COVID-19 pandemic has placed additional demands on health professionals, including pharmacists, to adapt to meet the society's demands (Austin, 2020; Watson et al., 2021). It is within this changing environment that the scope of pharmacy practice is broadening, with pharmaceutical public health recognised as a role within the profession and demanding a wider set of knowledge and skills for pharmacists (American Public Health Association, 2006; Root \& Vaney, 2017). The International Pharmaceutical Federation have recognised 21 broad development goals for the pharmacy profession (International Pharmaceutical Federation, 2020a), with many of the goals embracing public-health focused outcomes.

Pharmaceutical public health is one of the four domains recognised by the International Pharmaceutical Federation's Global Competency Framework Version 2 (International Pharmaceutical Federation, 2020b) and incorporates emergency response, health promotion, and medicines information and advice.

Public health and pharmacy have evolved as separate professions, inferring that there may be foundational public health principles, skills or competencies that may not have been included in pharmacy training for the provision of pharmaceutical public health services (Meyerson, Ryder, \& Richey-Smith, 2013). Although 
evidence-based preventive public health services such as smoking cessation and weight management delivered through community pharmacies have been found to improve health outcomes (Thomson et al., 2019), further standardised and consistent training may be required for pharmacists to increase effectiveness of services and impact upstream indicators such as health inequity and appropriate access to care (Wenger et al., 2016; Agomo et al., 2018; Thomson et al., 2019). Furthermore, the incorporation of public health concepts, skills and practice-based learning into pharmacy curricula and ongoing professional development has been recommended (Nemire et al., 2010; Eades, Ferguson, \& O'Carroll, 2011; Palombi, Kading, \& Hayes, 2013; Addo-Atuah, 2014; Strand, Davidson, \& Schulze, 2017; Agomo et al., 2018).

Alignment between public health competencies and pharmacy practice frameworks or standards has occurred in the United Kingdom (UK) (Bryson et al., 2014) and the United States of America (USA) (Covvey et al., 2016); however, this work has not been completed in other countries. Australia stands as an example of this, where pharmacy services with a public health focus, involving health promotion, prevention or protection (Dineen-Griffin et al., 2020; Pharmaceutical Society of Australia, 2018) have been developed, based on relevant pharmacy standards.

Consideration of public health competencies may add to the impact and relevance of services. The aim of this scoping review is to describe competencies identified in international literature that will enable pharmacists to effectively contribute to public health, with the view to applying results from the Australian situation. This is important to ensure that global development goals and competencies (International Pharmaceutical Federation, 2020a, 2020b) are applied according to the characteristics of individual countries. The results of the review will be applicable to professional organisations and educators, as evidence on which to base the future alignment of competencies and education, and will be of particular interest to countries where development of pharmaceutical public health is required.

\section{Methods}

\section{Scoping review}

A scoping review was determined as the ideal form of review process for this topic, as it allowed the collection of a broad overview of the intersection of pharmacy and public health from both peer-reviewed and grey literature (Munn et al., 2018). The review was undertaken according to the methodology published by the Joanna Briggs Institute (Joanna Briggs Institute, 2015) and reporting followed the PRISMA Extension for Scoping Reviews (PRISMA-ScR) (Tricco et al., 2018).

\section{Definitions}

Definitions of terms within the public health field may be used interchangeably and interpreted differently according to jurisdiction, country or discipline (Koplan et al., 2009; Roux, 2016). To assist in selection of papers and clarity of terms, the Global Charter for the Public's Health (Lomazzi, 2016) was used to establish a background reference for defining 'public health'. Public health is considered to comprise of health promotion, prevention and protection as services which are underpinned by the functions of governance, advocacy, capacity and information (Lomazzi, 2016). Additionally, models outlining public health and primary care (Levesque et al., 2013; AAFP Integration of Primary Care and Public Health Work Group, 2015) were used to provide further guidance in considering the difference between individualised clinical care and that which is directed towards populations.

Pharmaceutical public health has been defined as "the application of pharmaceutical knowledge, skills and resources to the science and art of preventing disease, prolong life, promoting, protecting and improving health for all through organised efforts of society" (Walker, 2000, p.340). In this review, a competency is viewed as the knowledge, skills, behaviours and attitudes of a pharmacist that develops through training, education and experience (International Pharmaceutical Federation, 2012). A competency framework is a set of competencies grouped together to allow support of professional performance and development (International Pharmaceutical Federation, 2012).

\section{Search strategy}

A search of peer-reviewed and grey literature was conducted between July 2019 and February 2020. Peer-reviewed papers were located by searching the databases Medline (Ovid), Scopus, CINAHL, Informit and ERIC. The search terms used were based on the key words "pharmacy" and "public health" and "competenc*", with MeSH terms and key words adapted for the requirements of each database. Search terms were tested to ensure the identification of appropriate papers (Arksey \& O'Malley, 2005). The search strategy for Medline (Ovid) was "Pharmacists" or "Pharmacy" or "Pharmaceutical Services" and "public health" or "Public Health" or "Health Promotion" or "health protection" and "Health Knowledge", "Attitudes", "Practice" or "competenc*" 
or "Education", "Public Health Professional" or "Competency-based Education" or "Education", "Pharmacy". Grey literature was searched systematically by using three of Godin et al's suggested searching strategies: grey literature databases, customised Google searches and targeted websites (Godin et al., 2015). Handsearching of articles cited in included papers was conducted for identification of further potential inclusions.

\section{Screening process}

Duplicates were removed from the results of the search strategies and the remaining records were screened according to defined inclusion and exclusion criteria (Table I). Title and abstract screening were conducted by the primary investigator, with $25 \%$ of titles checked by a second reviewer. Inconsistencies were resolved by discussion and consensus. The primary investigator subsequently screened full text of articles, with $25 \%$ checked by the second reviewer. Discussion by all investigators to reach consensus was used when agreement was not reached by two reviewers.

Table I: Inclusion and exclusion criteria

\begin{tabular}{l}
\hline \multicolumn{1}{c}{ Inclusion criteria } \\
\hline Pharmacy practice or pharmacy training \\
\hline Public health \\
\hline Interprofessional activities or topics that included \\
pharmacists or pharmacy students \\
\hline Description or list of competencies or learning outcomes \\
\hline Published after the year 2000 \\
\hline Original research articles, expert opinion or review articles \\
\hline Reports from professional organisations \\
\hline Competency frameworks relating to elements of \\
pharmaceutical public health practice \\
\hline \multicolumn{1}{c}{ Exclusion criteria } \\
\hline Letters to Editor, notes, abstracts or protocols \\
\hline Descriptions of knowledge or skills in therapeutic or clinical \\
areas \\
\hline Languages other than English \\
\hline Competencies or educational outcomes drawn verbatim \\
from included competency frameworks \\
\hline frameworal competency frameworks (of whole scope of \\
\hline
\end{tabular}

\section{Data charting}

Each paper was charted by the primary investigator according to characteristics including: first author, year of publication, country, type of study, level of evidence as defined by Joanna Briggs Institute (Joanna Briggs Institute \& University of Adelaide, 2013), pharmacy setting, public health activity or function (Lomazzi, 2016), study objectives, intervention, outcomes and target group (pharmacy or interprofessional). Charting results were confirmed by the second reviewer for $25 \%$ of included papers. In accordance with the scoping study methodology, no formal assessment of study quality was completed (Joanna Briggs Institute, 2015). Competencies or learning objectives were mapped into a matrix of Australian pharmacy competencies (Pharmaceutical Society of Australia, 2016) versus Australian public health educational outcomes (Council of Academic Public Health Institutions Australia, 2016). These pre-existing documents were chosen as the references for most representative of pharmacy or public health practice in Australia. Inductive coding of competencies and themes was also undertaken.

\section{Results}

A total of 2397 records were identified by the search, with the full text of 317 papers assessed for eligibility. With 259 papers unable to fulfil inclusion and exclusion criteria, a total of 58 were included for analysis in the review. Figure 1 outlines the results of the selection process.

\section{Study characteristics}

Included papers were published between 2002 and 2020 , with the majority $(n=35)$ originating from the USA. Other countries represented included the UK $(n=8)$, Australia $(n=3)$, and African countries $(n=2)$. Indonesia, Malaysia, Singapore, Canada and Brazil were each represented by one paper, while five were published by international collaborators. Pharmacists were the profession of interest in 39 papers, while 19 referred to multiple health professions. Approximately half $(n=32)$ of the papers pertained to the pharmacy student setting. The development of competencies was described in 20 papers, with the remainder using competencies or objectives in an educational intervention $(n=24)$ or alternatively, discussing competencies as an outcome or theme $(n=14)$. A summary of the papers is outlined in Table II. 


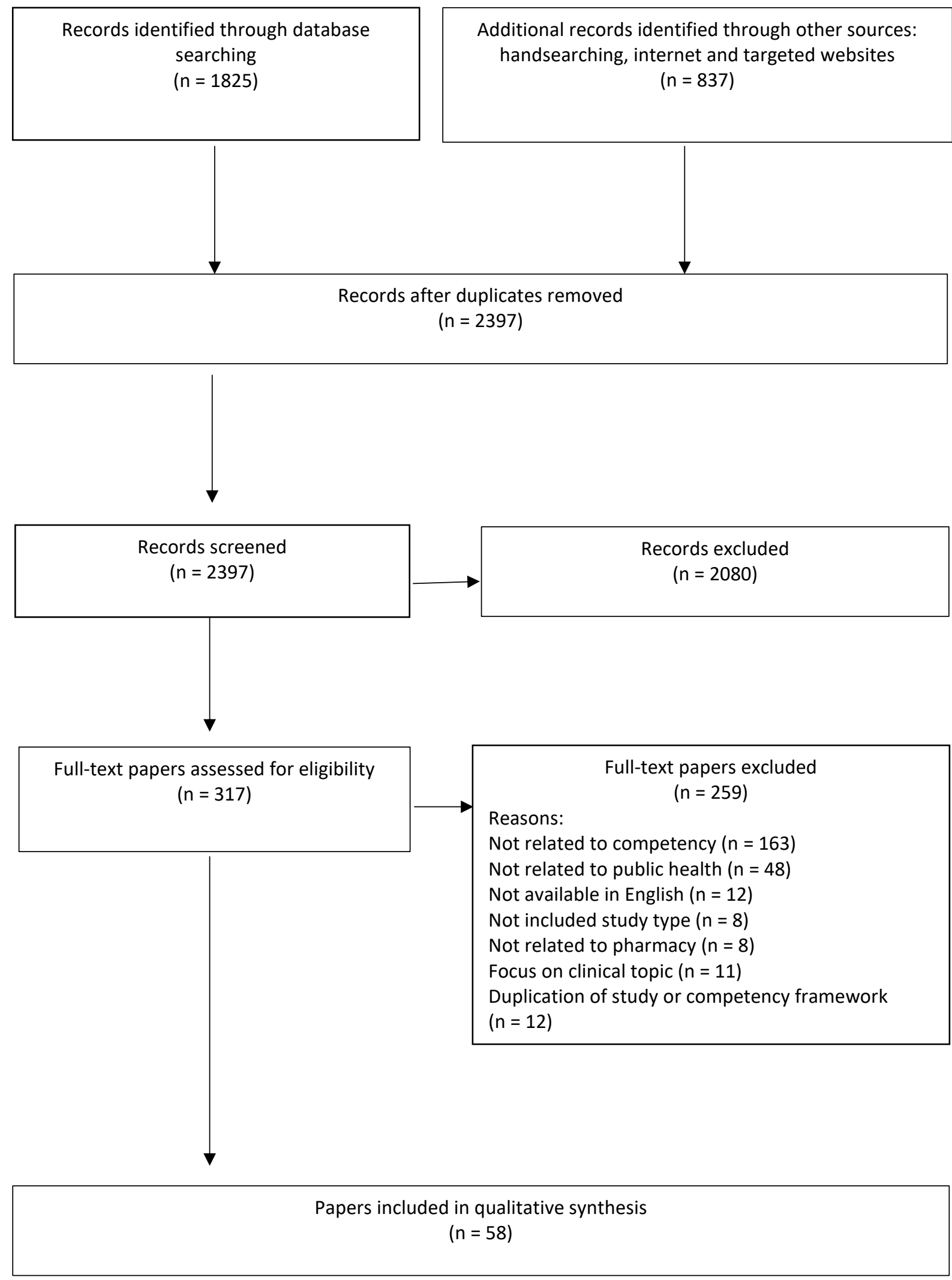

Figure 1: Paper selection process

(Adapted from PRISMA flow diagram (Moher et al., 2009) 
Table II: Characteristics of included papers

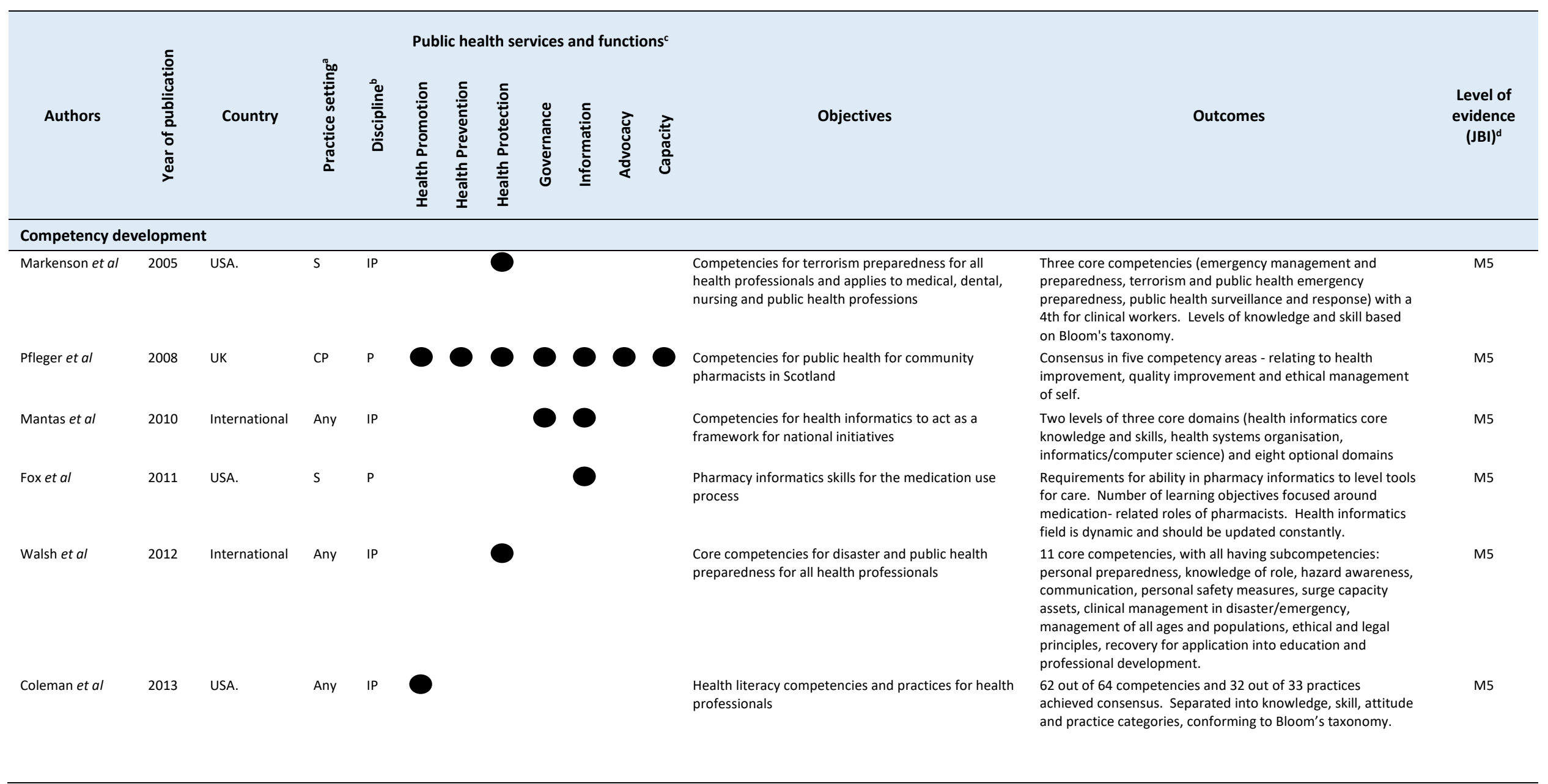

apharmacy practice setting of relevance $(S=$ student undergraduate or postgraduate, $C P=$ community pharmacy, Other $=$ other pharmacy setting to $C P$ or student, Any $=$ pharmacy practice setting not specified)

bDiscipline (IP= multidisciplinary or interprofessional setting which includes pharmacy, $\mathrm{P}=$ pharmacy only setting)

cPublic Health Services and Functions according to the Global Charter for the Public's Health (Lomazzi, 2016)

$\mathrm{d} M=$ meaningfulness studies, $\mathrm{E}=$ =effectiveness studies (Joanna Briggs Institute, 2015) 
Table II: Characteristics of included papers

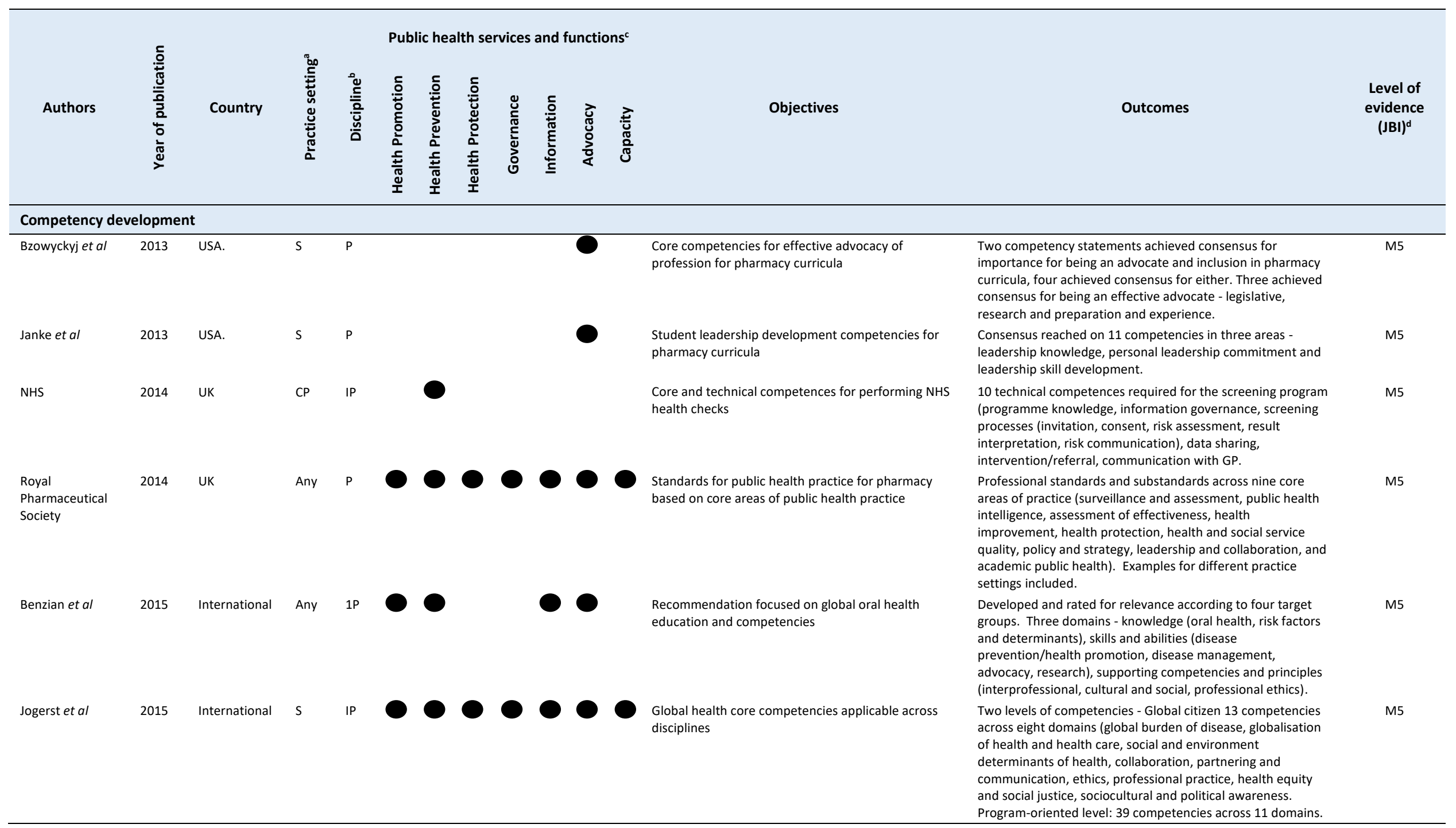


Table II: Characteristics of included papers

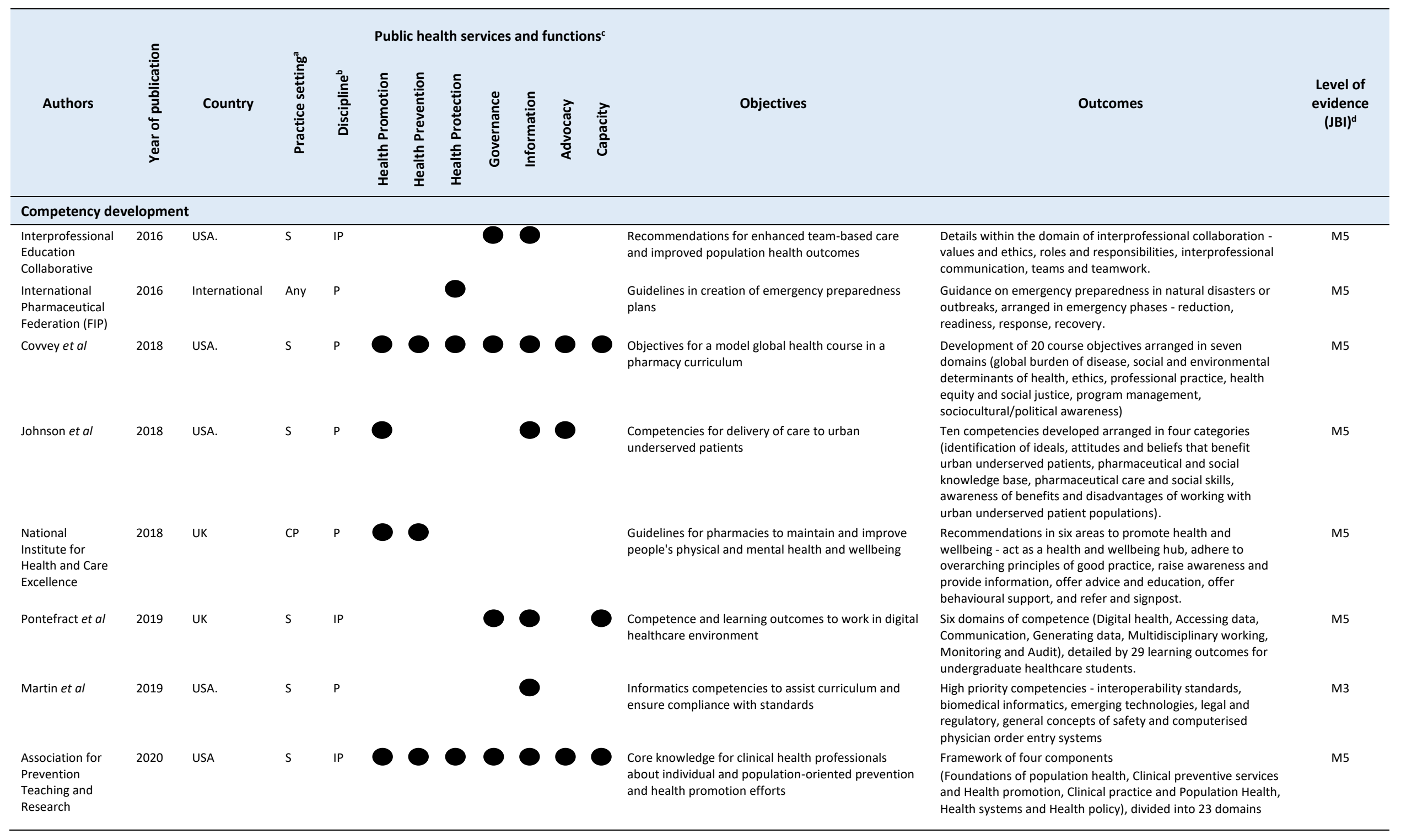


Table II: Characteristics of included papers

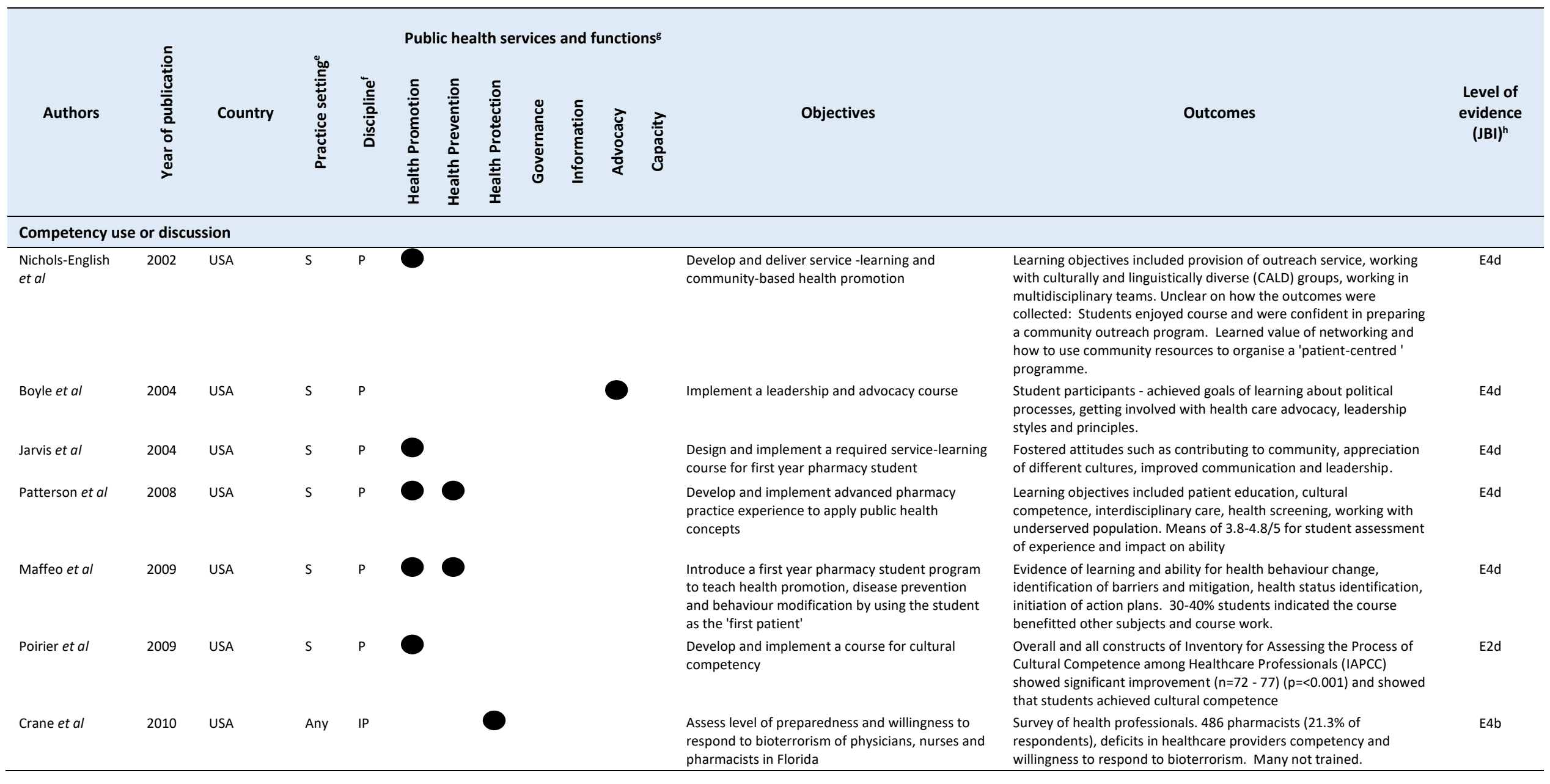

ePharmacy practice setting of relevance $(S=$ student undergraduate or postgraduate, $\mathrm{CP}=$ community pharmacy, Other = other pharmacy setting to $\mathrm{CP}$ or student, Any = pharmacy practice setting not specified).

'Discipline (IP= multidisciplinary or interprofessional setting which includes pharmacy, $\mathrm{P}=$ pharmacy only setting

BPublic Health Services and Functions according to the Global Charter for the Public's Health (Lomazzi, 2016)

${ }^{\mathrm{h}} \mathrm{M}=$ =meaningfulness studies, E=effectiveness studies (Joanna Briggs Institute, 2015) 
Table II: Characteristics of included papers

\begin{tabular}{|c|c|c|c|c|c|c|c|c|c|c|c|c|c|}
\hline \multirow[b]{2}{*}{ Authors } & \multirow[b]{2}{*}{ 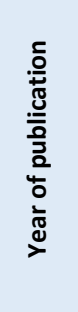 } & \multirow[b]{2}{*}{ Country } & \multirow[b]{2}{*}{ 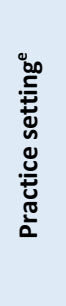 } & \multirow[b]{2}{*}{ 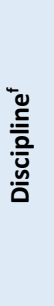 } & \multicolumn{6}{|c|}{ Public health services and functions $\mathrm{g}$} & \multirow[b]{2}{*}{ Objectives } & \multirow[b]{2}{*}{ Outcomes } & \multirow[b]{2}{*}{$\begin{array}{l}\text { Level of } \\
\text { evidence } \\
(\mathrm{JBI})^{\mathrm{h}}\end{array}$} \\
\hline & & & & & 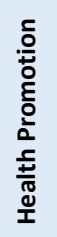 & 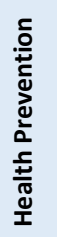 & 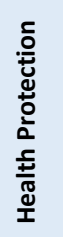 & 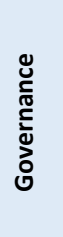 & 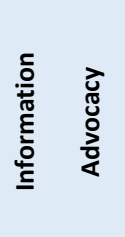 & $\begin{array}{l}\frac{2}{0} \\
\frac{2}{\pi} \\
\frac{0}{3} \\
\text { s }\end{array}$ & & & \\
\hline \multicolumn{14}{|c|}{ Competency use or discussion } \\
\hline Devraj et al & 2010 & USA & s & $P$ & & & & & & & $\begin{array}{l}\text { Implement and assess active-learning exercises in } \\
\text { health literacy in improving student knowledge } \\
\text { and confidence in a pharmacy course }\end{array}$ & $\begin{array}{l}\text { Learning outcomes included identification of low health literacy, } \\
\text { associated behaviours and use of strategies to help patients. } \\
\text { Increase in confidence to perform learning outcomes ( } p<0.01 \text { for } \\
\text { most outcomes, } p<=0.05 \text { for one). Knowledge increased from } \\
77.57 \text { - 88.56. Students agreed it increased knowledge. }\end{array}$ & E2d \\
\hline Packard et al & 2010 & USA & s & $P$ & & & & & & & $\begin{array}{l}\text { Implement an elective course to teach screening } \\
\text { for CV risk }\end{array}$ & $\begin{array}{l}\text { Learning objectives included skills in Cardiovascular health (CV) } \\
\text { screening. Increase in knowledge }(p=<0.001) \text {. Confidence increased } \\
\text { in screening and was retained after four months }(p<0.001) \text {. }\end{array}$ & E2d \\
\hline Rutland et al & 2010 & UK & $\mathrm{CP}$ & IP & & & & & & & $\begin{array}{l}\text { Describe information needs of frontline public } \\
\text { health workforce }\end{array}$ & $\begin{array}{l}\text { Pharmacist needed training in effective internet information } \\
\text { searching, knowledge of what information is available and targeted } \\
\text { bulletins to cut down information overload. Training for all } \\
\text { professionals was recognised as IT skills, signposting for information, } \\
\text { searching electronic databases. }\end{array}$ & M3 \\
\hline Saini et al & 2011 & Australia & S & IP & & & & & & & $\begin{array}{l}\text { Develop implement and evaluate an } \\
\text { interprofessional learning module focused on } \\
\text { health promotion }\end{array}$ & $\begin{array}{l}\text { Learning objectives included working interprofessionally, team work, } \\
\text { health education, recognise effect of policy, No increase in knowledge } \\
\text { score, significant improvement in attitudes scale }(p<0.003), \text { no } \\
\text { change in overall Readiness for Interprofessional Learning Scale Score } \\
\text { (RIPLS) but significant improvement in teamwork and collaboration } \\
\text { subscale }(p=0.047) \text {. Students valued opportunity and helped them } \\
\text { appreciate public health role and roles of other professionals. }\end{array}$ & E2d \\
\hline McCaig et al & 2011 & UK & $\mathrm{CP}$ & $P$ & & & & & & & $\begin{array}{l}\text { Explore community pharmacists' activities and } \\
\text { views on providing advice on alcohol use }\end{array}$ & $\begin{array}{l}\text { Low level of service provision. Knowledge and confidence of } \\
\text { pharmacists needs boosting to enable effective provision. Least } \\
\text { confident in basic skills of public health (e.g. screen, other services, } \\
\text { responding appropriately to other situations). }\end{array}$ & E4b \\
\hline Abraham et al & 2012 & USA & Any & IP & & & & & & & $\begin{array}{l}\text { Develop and implement bioterrorism continuing } \\
\text { education for rural health professionals }\end{array}$ & $\begin{array}{l}641 \text { participants - Small number of pharmacist participants (5). } \\
\text { Participation in five tabletop scenarios. Positive evaluations from } \\
\text { participants. Limitation of small number of pharmacists. } \\
\text { Recommendation as key players in exercises as a significant role in } \\
\text { threat preparedness and disaster response. }\end{array}$ & E4d \\
\hline Haddad et al & 2012 & USA & s & $\mathrm{P}$ & & & & & & & $\begin{array}{l}\text { Implement and assess pharmacy practice } \\
\text { experience in community engagement - impact } \\
\text { on student confidence and ability to provide } \\
\text { community-based services }\end{array}$ & $\begin{array}{l}\text { Learning objectives included collaboration with others, assist } \\
\text { community health outreach, deliver health education, practice } \\
\text { cultural competency. Significant increase in student competence and } \\
\text { confidence - most increase in formulating appropriate care plans for } \\
\text { people in community-based outreach programs and skill in delivering } \\
\text { educational programs to community. }\end{array}$ & E2d \\
\hline
\end{tabular}


Table II: Characteristics of included papers

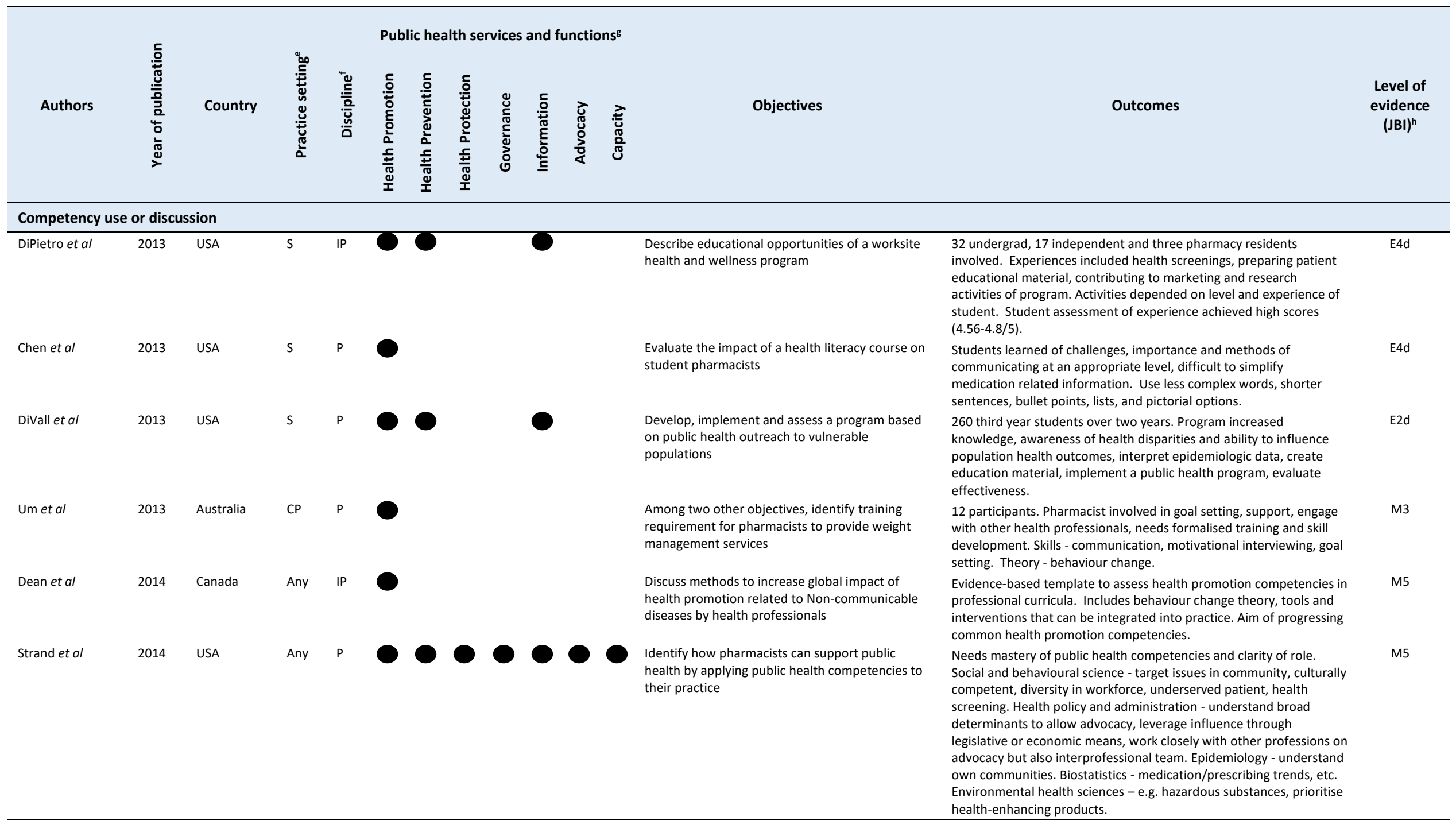


Table II: Characteristics of included papers

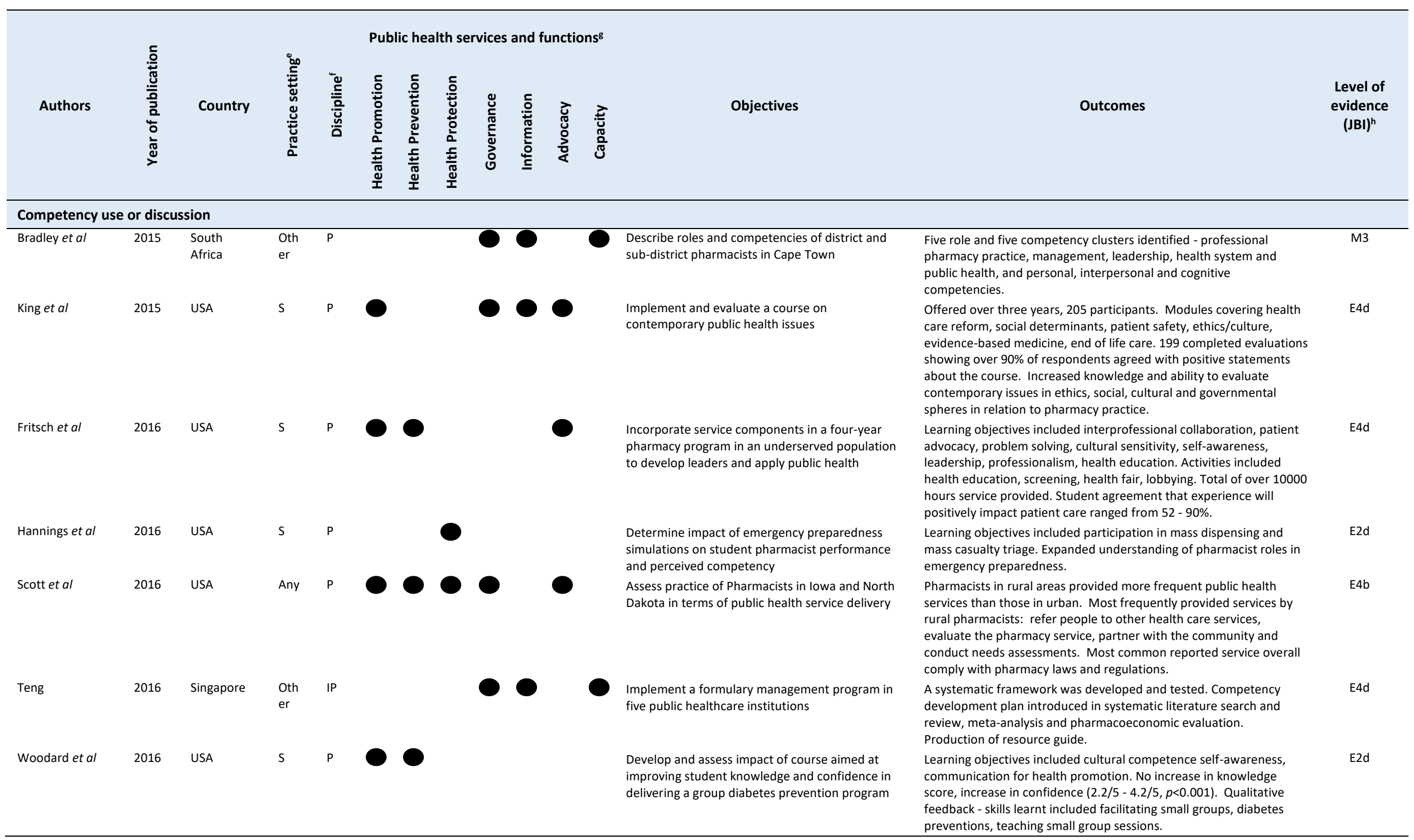


Table II: Characteristics of included papers

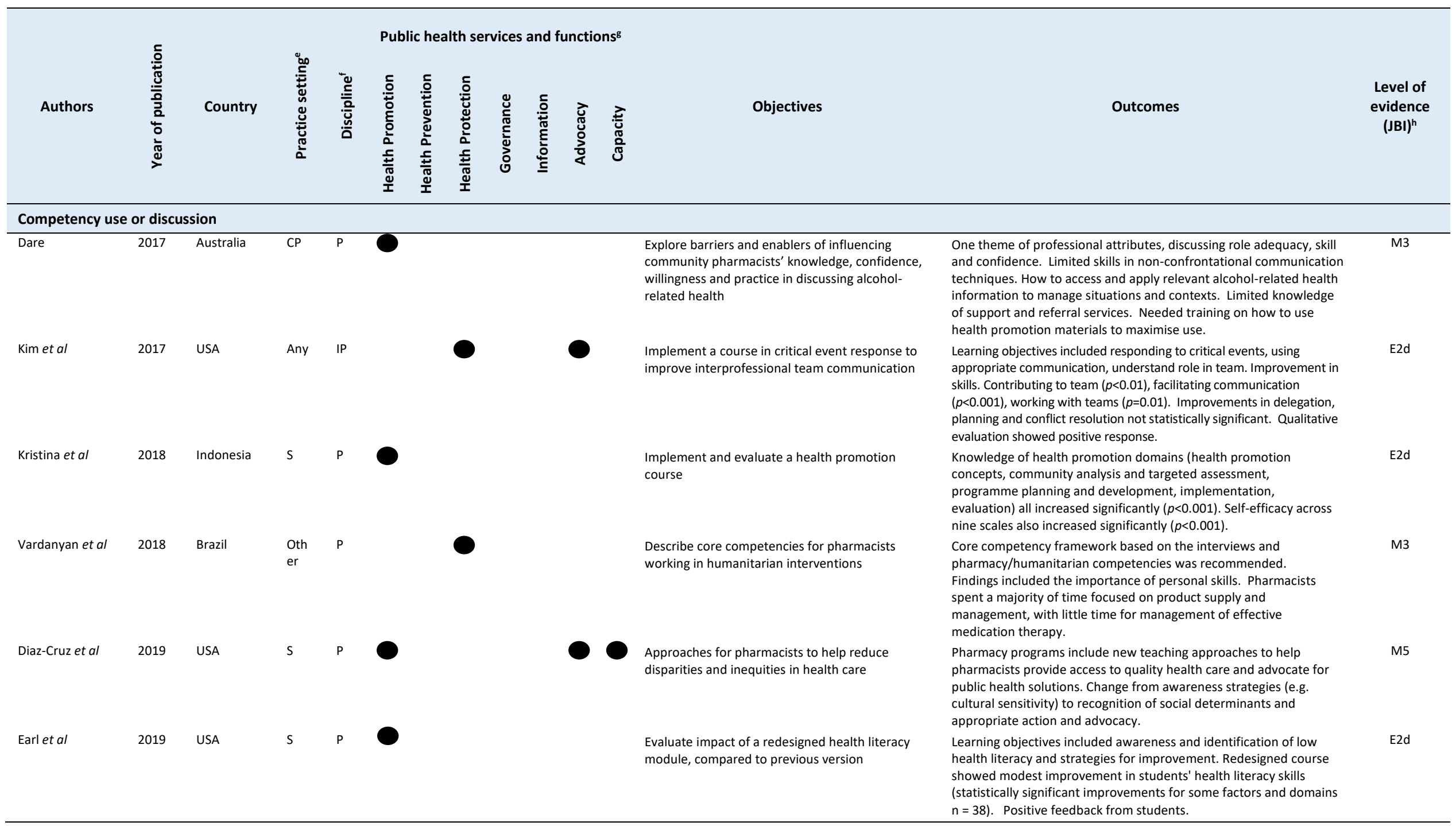


Table II: Characteristics of included papers

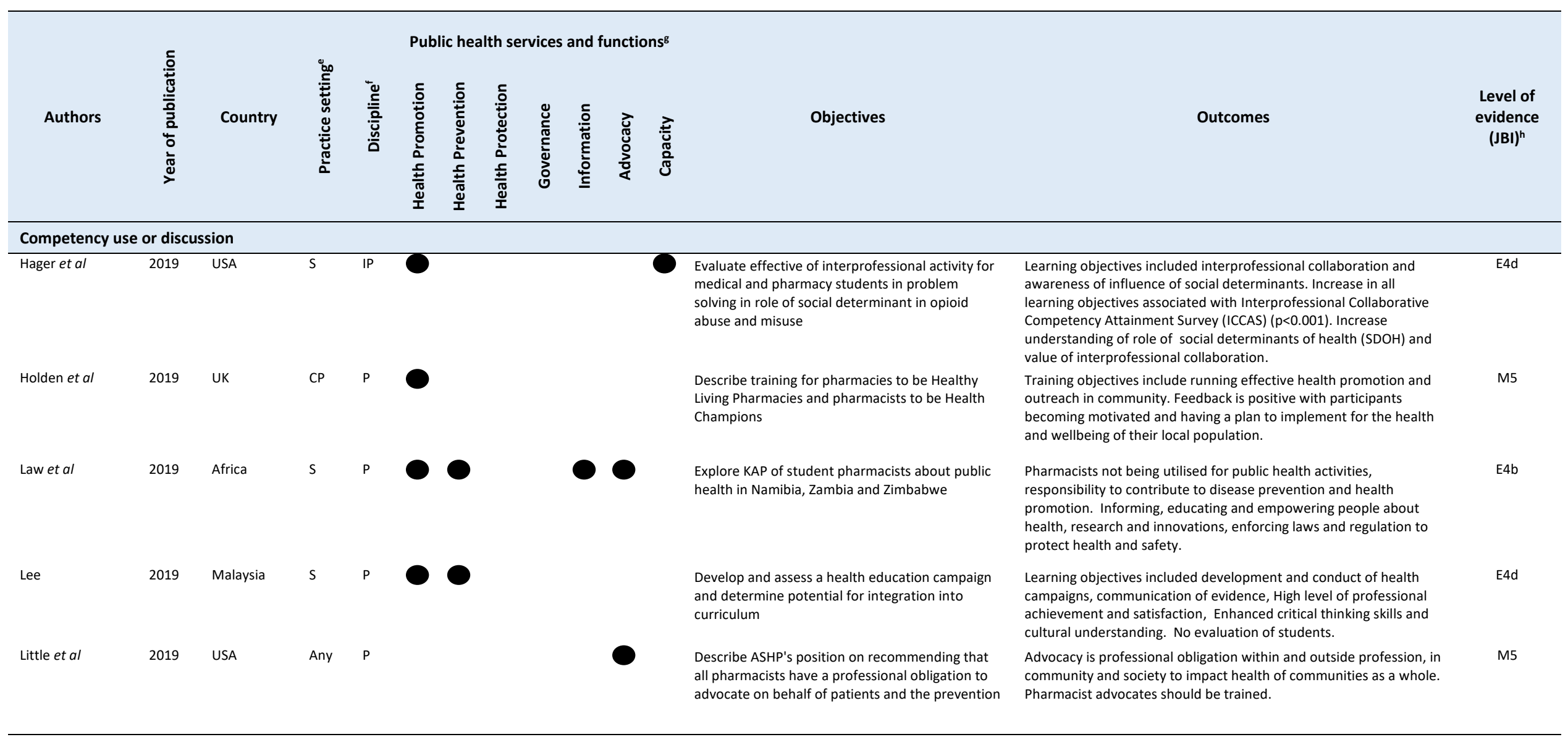




\section{Topics of included papers}

Public health competencies for pharmacy were described by two competency frameworks developed in the UK (Pfleger et al., 2008; Bryson et al., 2014) and were discussed broadly by one paper from the USA (Strand \& Miller, 2014). Other papers referring directly to public health for pharmacists presented public health modules for pharmacy students (Patterson, 2008; King \& Egras, 2015), assessed public health service delivery by pharmacies, (Scott et al., 2016) and discussed the information needs of health professionals delivering public health services (Rutland \& Smith, 2010).

Elements of public health practice such as inclusion of social determinants of health (Hager et al., 2019), addressing health inequity (Diaz-Cruz, 2019; Little et al., 2019), caring for vulnerable populations (DiVall et al., 2013; Fritsch et al., 2016; Johnson \& Traynor, 2018) and providing humanitarian assistance (Vardanyan, Mosegui, \& Miranda, 2018) were also addressed. Other topics represented in papers included health promotion or disease prevention (including health literacy) $(n=22)$ (Nichols-English, White, \& Brooks, 2002; Jarvis et al., 2004; Maffeo et al., 2009; Packard et al., 2010; Devraj et al., 2010; McCaig, Fitzgerald, \& Stewart, 2011; Saini et al., 2011; Chen, Noureldin, \& Plake, 2013; Coleman, Hudson, \& Maine, 2013; Um et al., 2013; DiPietro et al., 2013; NHS Health Check national competency and training working group, 2014; Dean et al., 2014; Woodard et al., 2016; Dare et al., 2017; Kristina, Yulianto, \& Prabandari, 2018; National Institute for Health and Care Excellence, 2018; Earl et al., 2019; Holden \& Evans, 2019; Healthy People Curriculum Task Force, 2020; Law et al., 2019; Lee, 2019), disaster and emergency responses $(n=7)$ (Markenson, DiMaggio, \& Redlener, 2005; Crane et al., 2010; Abraham et al., 2012; Walsh et al., 2012; Hannings et al., 2016; International Pharmaceutical Federation, 2016; Kim et al., 2017), community-based services or engagement $(n=5)$ (Haddad et al., 2012; DiVall et al., 2013; Fritsch et al., 2016; Johnson \& Traynor, 2018; Diaz-Cruz, 2019), global health $(n=4)$ (Benzian et al., 2015; Jogerst et al., 2015; J. R. Covvey \& Ryan, 2018;), health informatics $(n=4)$ (Mantas et al., 2010; Fox et al., 2011; Martin et al., 2019; Pontefract \& Wilson, 2019), leadership and advocacy $(n=4)$ (Boyle, Beardsley, \& Hayes, 2004; Bzowyckyj \& Janke, 2013; Janke, Traynor, \& Boyle, 2013; Little et al., 2019), policy, planning or management topics $(n=2)$ (Bradley, Lehmann, \& Butler, 2015; Teng et al., 2016), cultural competency $(n=1)$ (Poirier et al., 2009) and interprofessional practice $(n=1)$ (Interprofessional Education Collaborative, 2016). All services and functions of public health (Lomazzi, 2016) were represented, with health promotion the most common, being discussed in 37 of the 58 papers. The public health functions of capacity $(n=11)$ and governance $(n=13)$ were least represented.

\section{Relevance to pharmacy and public health frameworks}

Competency statements from papers were mapped into a matrix of pharmacy and public health competencies. The results in terms of numbers of papers is provided in Figure 2 for those describing competency development, while Figure 3 shows results for the remaining papers which used or discussed competencies.

Papers presenting competency frameworks included competencies from all pharmacy domains and public health practice areas, while two intersections of matrix elements (communication/professional public health practice and medicines management/health promotion) dominated the results for papers using or discussing competencies. Results from the thematic analysis were then grouped according to the five Australian pharmacy competency domains: professionalism and ethics, communication and collaboration, medicines management and patient care, leadership, and education and research (Pharmaceutical Society of Australia, 2016). A summary of the major themes and areas of competency is outlined in Table III.

\section{Professionalism and ethics}

Competency statements contributing to the first pharmacy domain of professionalism and ethics discussed the roles and professional qualities of pharmacists, partnership with people and the communities in addition to understanding and applying policy as well as legislation relevant to practice.

\section{Roles and professional qualities}

Competencies in upholding professionalism were described (Pfleger et al., 2008; Walsh et al., 2012; Bzowyckyj \& Janke, 2013; Bryson et al., 2014; Benzian et al., 2015; J. R. Covvey \& Ryan, 2018; Law et al., 2019). The display of professional and ethical behaviour, leadership, respect and understanding for others were described as important foundational attributes for pharmacists in public health roles (Walsh et al., 2012; Bzowyckyj \& Janke, 2013; Bryson et al., 2014; Benzian et al., 2015; Bradley et al., 2015; J. R. Covvey \& Ryan, 2018; Johnson \& Traynor, 2018;). The competencies identified required pharmacists to be confident of their role and scope of practice (Bradley et al., 2015; Interprofessional Education Collaborative, 2016; Kim et al., 2017; J.R. Covvey \& Ryan, 2018). This attribute, together with an understanding of other health professionals' roles, can enhance professional respect and the conduct of interprofessional activities (Crane et al., 2010; Benzian et al., 2015; Jogerst et al., 2015; Hager et al., 2019; Interprofessional Education Collaborative, 2016; Kim et al., 2017; Saini et al., 2011). 


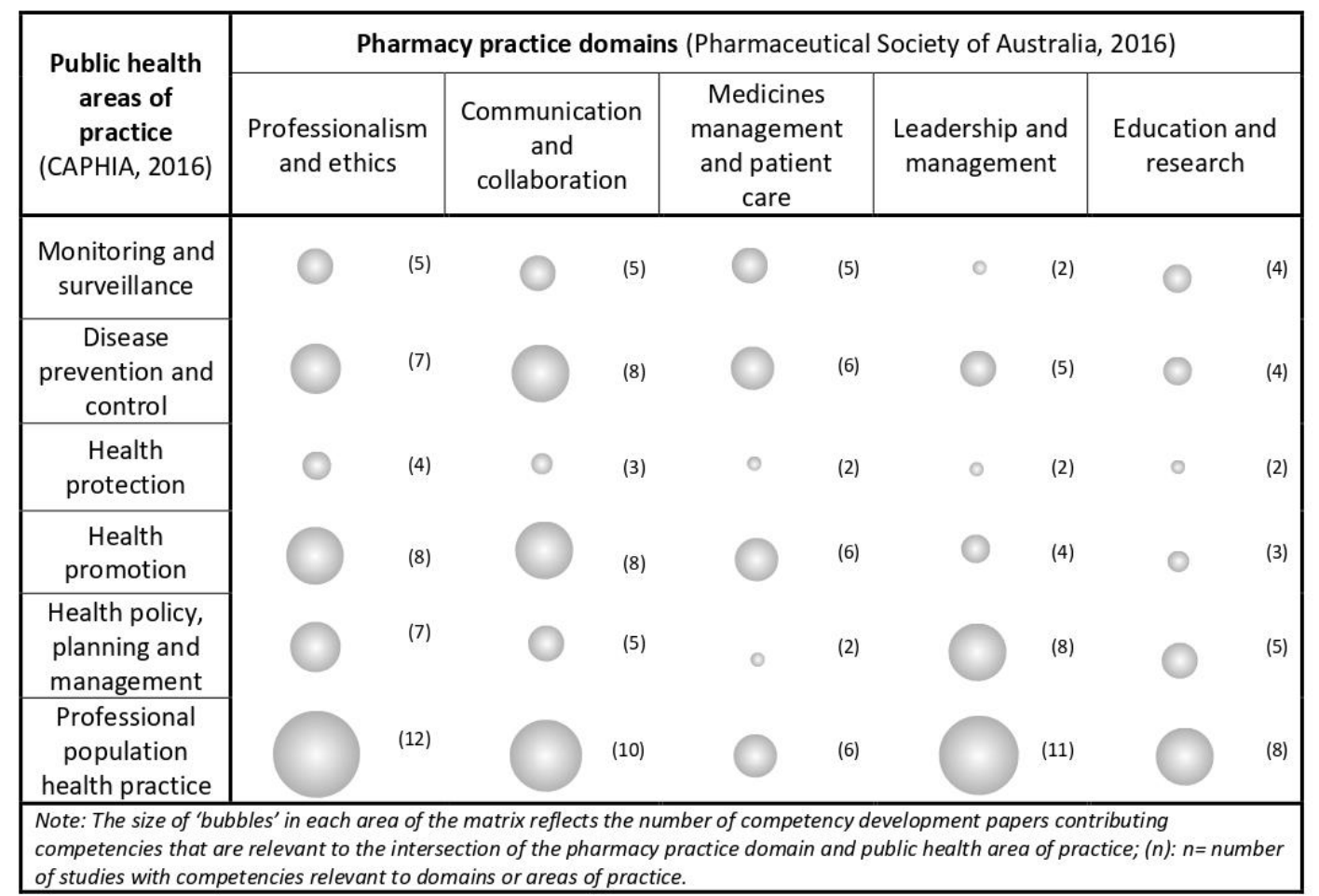

Figure 2: Numbers of competency framework papers containing competency statements according to pharmacy practice domains and public health areas of practice

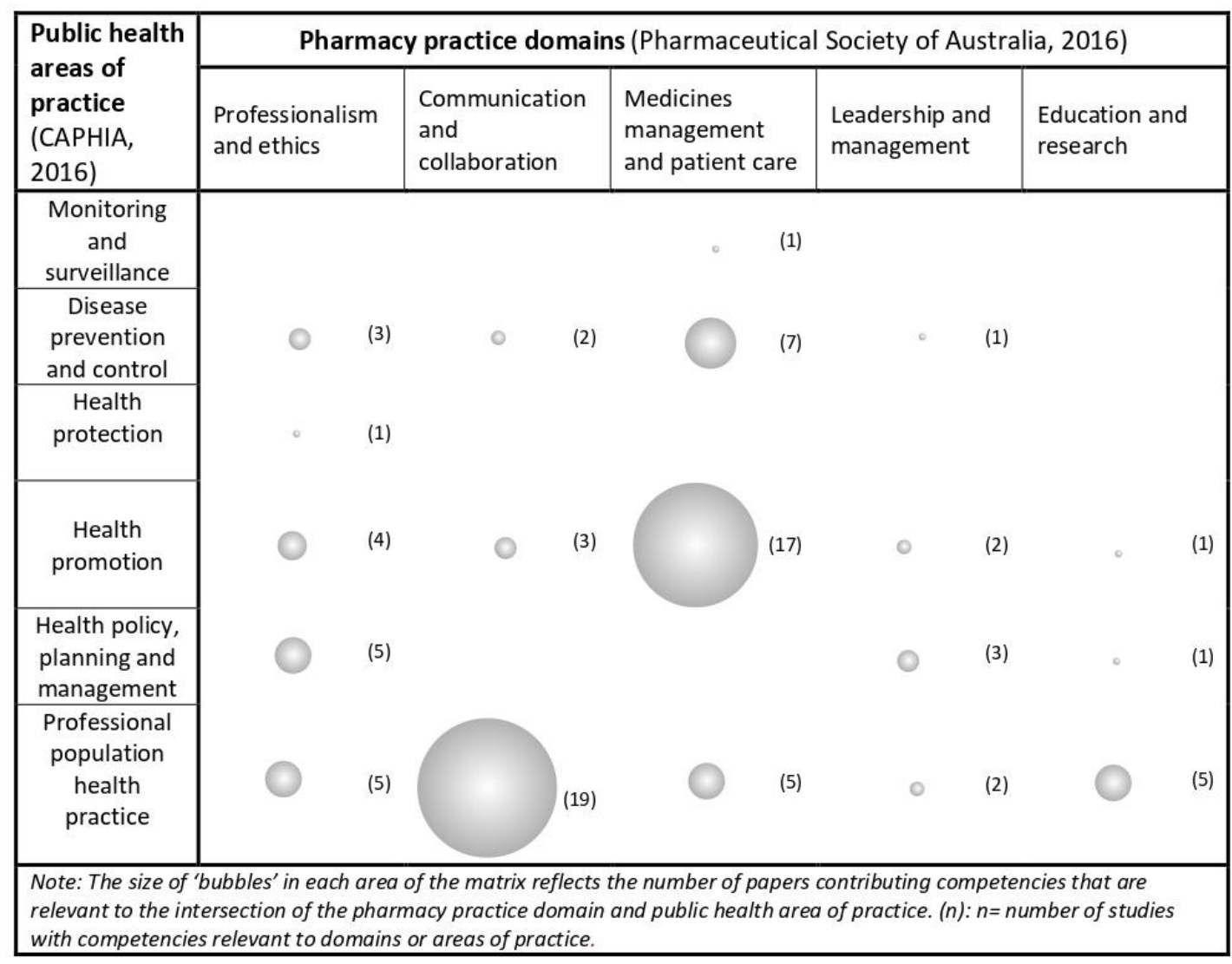

Figure 3: Numbers of papers describing or using competencies containing competency statements according to pharmacy practice domains and public health areas of practice 
Table III: Major themes and areas of competency

\begin{tabular}{llll}
\hline $\begin{array}{l}\text { Competency } \\
\text { Domain }\end{array}$ & Theme & Summary of competencies & References \\
\hline $\begin{array}{l}\text { Professionalism } \\
\text { and ethics }\end{array}$ & $\begin{array}{l}\text { Roles and } \\
\text { professional } \\
\text { qualities }\end{array}$ & $\begin{array}{l}\text { Confidence in role and scope of } \\
\text { practice }\end{array}$ & NHS,(2014), Dare et al.,(2017), Walsh et al.,(2012), \\
& & Markenson et al.,(2005), International Pharmaceutical \\
& & Federation,(2016), Hannings et al., (2016), Mantas et al., \\
(2010), Boyle et al.,(2004), Bradley et al.,(2015)
\end{tabular}

Partnership with Contribution to community community

Policy and legislation

Impact of socioeconomic determinants of health
Leadership, ethical principles and respect for others

Consideration of community needs

Compliance with legislation

Participation in policy processes

Advocacy

Skills across all modes of communication

skills and

techniques

and

collaboration
Interprofessional collaboration

Pharmaceutical Society of Australia,(2016), Diaz-Cruz,(2019), Johnson \& Traynor,(2018), Vardanyan et al.,(2018), Devraj et al.,(2010), DiPietro et al.,(2013), Dare et al.,(2017), Crane et al.,(2013), Hannings et al.,(2016), Kim et al.,(2017), Haddad et al.,(2012), Martin et al.,(2019), Bradley et al.,(2015)

Bryson et al.,(2014), Pfleger et al.,(2008), King \& Egras,(2015), Diaz-Cruz,(2019), Little et al.,(2019), NHS,(2014), Dean et al.,(2014), Hannings et al.,(2016), Kim et al.,(2017), Bradley et al.,(2015), Teng et al.,(2016)

Bryson et al.,(2014), Covvey et al.,(2016), Rutland \& Smith,(2010), Diaz-Cruz,(2019), Johnson \& Traynor,(2018), NHS,(2014), Lee,(2019), Dean et al.,(2014), Hannings et al.,(2016), Kim et al.,(2017), Haddad et al.,(2012), Benzian et al.,(2015)

Bryson et al.,(2014), Pfleger et al.,(2008), King \& Egras,(2015), Diaz-Cruz,(2019), NHS,(2014), Chen et al.,(2013), Kristina et al.,(2018), Hannings et al.,(2016), Kim et al.,(2017), Haddad et al.,(2012)

Bryson et al.,(2014), King \& Egras,(2015), Jarvis et al.,(2004), Dare et al.,(2017)., Law et al.,(2019), Covvey \& Ryan,(2018), Benzian et al.,(2015), Boyle et al.,(2004)

Bryson et al.,(2014), Pfleger et al.,(2008), King \& Egras,(2015), Hager et al.,(2019), NHS,(2014), Covvey \& Ryan,(2018), Fox et al.,(2011), Mantas et al.,(2010)

King \& Egras,(2015), Hager et al.,(2019), Johnson \& Traynor,(2018), NHS,(2014), Haddad et al.,(2012), Fox et al.,(2011), Mantas et al.,(2010), Teng et al.,(2016)

Bryson et al.,(2014), Pfleger et al.,(2008), Diaz-Cruz,(2019), Johnson \& Traynor,(2018), Fritsch et al.,(2016), Vardanyan et al.,(2018), NHS,(2014), Devraj et al.,(2010), Saini et al.,(2011), Woodard et al.,(2016), Um et al.,(2013), Dean et al.,(2014), Jarvis et al.,(2004), Walsh et al.,(2012), Crane et al.,(2010), Abraham et al.,(2012), Martin et al.,(2019), Mantas et al.,(2010), Bradley et al.,(2015)

Use of communication techniques based on theory

Use of team approaches
Use of communication techniques to influence behaviour

Bryson et al.,(2014), Pfleger et al.,(2008), Diaz-Cruz,(2019), NHS,(2014), Healthy People Curriculum Task Force,(2020), Packard et al.,(2010), DiPietro et al.,(2013), Kristina et al.,(2018), Holden \& Evans,(2019), Lee,(2019), Dean et al.,(2014), Boyle et al.,(2004), Teng et al.,(2016)

Healthy People Curriculum Task Force,(2020), Devraj et al.,(2010), Earl et al.,(2019), Lee,(2019)

Bryson et al.,(2014), Pfleger et al.,(2008), Strand \& Miller,(2014), King \& Egras,(2015), Johnson \& Traynor,(2018), Vardanyan et al.,(2018), NHS,(2014), Devraj et al.,(2010), Packard et al.,(2010), Chen et al.,(2013), Kristina et al.,(2018), Holden \& Evans,(2019), Um et al.,(2013), Markenson et al.,(2005), Crane et al.,(2010), Abraham et al.,(2012), Kim et al.,(2017), Haddad et al.,(2012), Pontefract \& Wilson,(2019), Boyle et al.,(2004), Bradley et al.,(2015) 
Table III: Major themes and areas of competency

\begin{tabular}{|c|c|c|c|}
\hline $\begin{array}{l}\text { Competency } \\
\text { Domain }\end{array}$ & Theme & Summary of competencies & References \\
\hline & \multirow[t]{2}{*}{$\begin{array}{l}\text { Cultural } \\
\text { competency }\end{array}$} & $\begin{array}{l}\text { Use of strategies that show } \\
\text { awareness of and respect for } \\
\text { individuals and patient-centredness }\end{array}$ & $\begin{array}{l}\text { Pfleger et al.,(2008), Strand \& Miller,(2014), Rutland \& } \\
\text { Smith,(2010), DiVall et al.,(2013), Fritsch et al.,(2016), } \\
\text { NHS,(2014), NICE,(2018), Healthy People,(2020), Maffeo et } \\
\text { al., (2009), Devraj et al.,(2010), DiPietro et al., (2013), } \\
\text { Hannings et al.,(2016), Janke et al.,(2013), Bradley et } \\
\text { al.,(2015), Teng et al.,(2016), Johnson \& Traynor,(2018), } \\
\text { Holden \& Evans,(2019) }\end{array}$ \\
\hline & & $\begin{array}{l}\text { Recognition of own beliefs and } \\
\text { behaviours }\end{array}$ & $\begin{array}{l}\text { Rutland \& Smith,(2010), Fritsch et al.,(2016), NHS,(2014), } \\
\text { Healthy People,(2020), Janke et al.,(2013), Bradley et } \\
\text { al.,(2015) }\end{array}$ \\
\hline $\begin{array}{l}\text { Medicines } \\
\text { management }\end{array}$ & $\begin{array}{l}\text { Health promotion } \\
\text { and disease } \\
\text { prevention }\end{array}$ & $\begin{array}{l}\text { Design, implementation and } \\
\text { evaluation of evidence-based } \\
\text { health promotion, disease } \\
\text { screening or prevention } \\
\text { interventions }\end{array}$ & $\begin{array}{l}\text { Bryson et al.,(2014), Pfleger et al.,(2008), Strand \& } \\
\text { Miller,(2014), Little et al.,(2019), NHS,(2014), Healthy } \\
\text { People,(2020), Maffeo et al.,(2009), Devraj et al.,(2010), } \\
\text { Packard et al.,(2010), Saini et al.,(2011), DiPietro et al., } \\
\text { (2013), Chen et al.,(2013), Earl et al.,(2019), Holden \& } \\
\text { Evans,(2019), Lee,(2019), Um et al.,(2013), Abraham et } \\
\text { al.,(2012), Haddad et al.,(2012), Benzian et al.,(2015), Teng et } \\
\text { al.,(2016) }\end{array}$ \\
\hline
\end{tabular}

Health literacy Identification and improvement of low health literacy by the use of appropriate tools and oral or written strategies

Self-assessment

Flexible and innovative thinking

Development and management of change

Management of programmes, resources and finances, data, quality and risk
Bryson et al.,(2014), Diaz-Cruz,(2019), DiVall et al.,(2013), Fritsch et al.,(2016), Fritsch et al.,(2016), McCaig et al.,(2011), Woodard et al., (2016), Hannings et al.,(2016), Janke et al.,(2013)

Johnson \& Traynor,(2018), Kim et al.,(2017), Pontefract \& Wilson,(2019), Boyle et al.,(2004), Bradley et al.,(2015)

King \& Egras,(2015), Walsh et al.,(2012), Boyle et al.,(2004)

Bryson et al.,(2014), Pfleger et al.,(2008), Fox et al.,(2011), Pontefract \& Wilson,(2019), Boyle et al.,(2004), Bradley et al.,(2015)

Bryson et al.,(2014), Pfleger et al.,(2008), King \& Egras,(2015), DiVall et al.,(2013), Vardanyan et al.,(2018), NHS,(2014), NICE,(2018), Kristina et al.,(2018), Jarvis et al.,(2004), Hannings et al.,(2016), Kim et al.,(2017), Covvey \& Ryan,(2018), Jogerst et al.,(2015), Benzian et al.,(2015), Martin et al.,(2019), Boyle et al.,(2004), Bzowyckyj \& Janke,(2013), Bradley et al.,(2015)

Bryson et al.,(2014), Pfleger et al.,(2008), Patterson,(2008), Little et al.,(2019), NHS,(2014), Saini et al.,(2011), Chen et al.,(2013), Dean et al.,(2014), Haddad et al.,(2012), Jogerst et al.,(2015), Benzian et al.,(2015), Martin et al.,(2019), Bzowyckyj \& Janke,(2013)

Use of data and data systems

Bryson et al.,(2014), Pfleger et al.,(2008), Patterson,(2008), Vardanyan et al.,(2018), NHS,(2014), Jarvis et al.,(2004), Covvey \& Ryan,(2018), Jogerst et al.,(2015), Benzian et al.,(2015), Martin et al.,(2019), Bzowyckyj \& Janke,(2013)

Provide education, mentoring or coaching
Pfleger et al.,(2008), Strand \& Miller,(2014), DiVall et al.,(2013), Jogerst et al.,(2015)

\section{Partnership with community}

An overarching theme related to professionalism was the importance of collaboration and interconnectedness for pharmacists. This was discussed at a number of levels with major concepts being the importance of partnerships with communities and people (Pfleger et al., 2008; Bryson et al., 2014) and the recognition of the impact of societal issues, such as social justice and health equity, on health 
(Pfleger et al., 2008; J.R. Covvey \& Ryan, 2018; Johnson \& Traynor, 2018;). It was identified that pharmacists are responsible for contributing to the community and its health and wellbeing (Jarvis et al., 2004; Pfleger et al., 2008; DiVall et al., 2013; Bryson et al., 2014; Jogerst et al., 2015; Interprofessional Education Collaborative, 2016; Scott et al., 2016; J. R. Covvey \& Ryan, 2018; Johnson \& Traynor, 2018; Law et al., 2019). The identification of factors that have impact on people's health and pharmacists contribution to community health assessments were described as important to inform appropriate pharmacy interventions (Boyle et al., 2004; Scott et al., 2016; Holden \& Evans, 2019; Law et al., 2019).

\section{Policy and legislation}

Knowledge and awareness of policy and policy processes was described as required by pharmacists (Boyle et al., 2004; Bryson et al., 2014; Saini et al., 2011; Benzian et al., 2015; Scott et al., 2016; Law et al., 2019; Little et al., 2019). Examples included having an understanding of national and state policies (Saini et al., 2011; Little et al., 2019) and using this knowledge to confidently participate in policy processes and advocacy on national and state issues affecting health (Benzian et al., 2015; Scott et al., 2016; Little et al., 2019), as well as professional activities such as emergency response (Crane et al., 2010).

\section{Communication and collaboration}

Competencies identified in the communication and collaboration domain emerged in 32 papers (English et al., 2002; Jarvis et al., 2004; Patterson, 2008; Pfleger et al., 2008; Maffeo et al., 2009;Crane et al., 2010; NicholsPackard et al., 2010; McCaig et al., 2011; Saini et al., 2011; Haddad et al., 2012; Bzowyckyj \& Janke, 2013; Coleman et al., 2013; DiPietro et al., 2013; Um et al., 2013; Bryson et al., 2014; Dean et al., 2014; NHS Health Check national competency and training working group, 2014; Bradley et al., 2015; Fritsch et al., 2016; International Pharmaceutical Federation, 2016; Interprofessional Education Collaborative, 2016; Scott et al., 2016; Woodard et al., 2016; Dare et al., 2017; Kim et al., 2017; Johnson \& Traynor, 2018; Earl et al., 2019; Holden \& Evans, 2019; Law et al., 2019; Lee, 2019; Pontefract \& Wilson, 2019; Healthy People Curriculum Task Force, 2020) with a broad range of required communication skills described. Communication skills were identified as being required for working in a culturally appropriate manner with individuals, patient/consumer groups and interprofessionally.

\section{Communication skills and techniques}

Communication techniques and strategies to encourage behaviour change, such as brief intervention and motivational interviewing, were important when working in health promotion or prevention activities with individuals or groups (Jarvis et al., 2004; Pfleger et al., 2008; Maffeo et al., 2009; McCaig et al., 2011; Saini et al., 2011; Um et al., 2013; Bryson et al., 2014; Dean et al., 2014; Bradley et al., 2015; Woodard et al., 2016; Johnson \& Traynor, 2018; National Institute for Health and Care Excellence, 2018; Holden \& Evans, 2019; Healthy People Curriculum Task Force, 2020).

Awareness of theory as the basis of communication intervention (Maffeo et al., 2009; Dean et al., 2014; Saini et al., 2011; Lee, 2019;) and the importance of non-confrontational communication techniques (Dare et al., 2017; Holden \& Evans, 2019) were also discussed. Papers addressing health literacy and advocacy detailed a range of further required communication skills such as the simplification of health information (Coleman et al., 2013; J.R. Covvey \& Ryan, 2018) and the ability to produce appropriate written materials (DiPietro et al., 2013; DiVall et al., 2013; Fritsch et al., 2016; Earl et al., 2019). The ability to clearly state key points in health issues, engage with stakeholders and use public relations and marketing methods allows pharmacists to act as advocates for health and also the pharmacy profession (Boyle et al., 2004; Bzowyckyj \& Janke, 2013; Fritsch et al., 2016). Competencies in communication and collaboration also featured as basic skills for the provision of public health activities such as responses in emergency or disaster situations (Markenson et al., 2005; Walsh et al., 2012; International Pharmaceutical Federation, 2016). Excellence in communication skills was seen as a basis for interprofessional working (Pfleger et al., 2008; Bryson et al., 2014; Interprofessional Education Collaborative, 2016) as well as working with groups of patients, individuals and communities (Bryson et al., 2014; Jogerst et al., 2015).

\section{Interprofessional collaboration}

Collaboration with other health professionals was identified as an important aspect of the theme of interconnectedness that appeared in the results. This was reflected in the number of papers addressing interprofessional competencies $(n=19)$ (Markenson et al., 2005; Crane et al., 2010; Mantas et al., 2010; Rutland \& Smith, 2010; Saini et al., 2011; Abraham et al., 2012; Walsh et al., 2012Coleman et al., 2013; DiPietro et al., 2013; Dean et al., 2014; NHS Health Check national competency and training working group, 2014; Benzian et al., 2015; Jogerst et al., 2015; Interprofessional Education Collaborative, 2016; Teng et al., 2016; Kim et al., 2017; Hager et al., 2019; Pontefract \& Wilson, 2019; Healthy People Curriculum Task Force, 2020). Of the papers presenting competency frameworks, half $(n=10)$ were directed 
towards an interprofessional audience (Markenson et al., 2005; Mantas et al., 2010; Walsh et al., 2012; Coleman et al., 2013; NHS Health Check national competency and training working group, 2014; Benzian et al., 2015; Jogerst et al., 2015; Interprofessional Education Collaborative, 2016; Pontefract \& Wilson, 2019; Healthy People Curriculum Task Force, 2020).

Interprofessional practice was specifically addressed in one paper which identified four core competency domains including values/ethics, roles/responsibilities, interprofessional communication and teamwork (Interprofessional Education Collaborative, 2016). Competency sets for an interprofessional target audience were also available in digital health/informatics (Mantas et al., 2010; Pontefract \& Wilson, 2019), disaster or emergency preparedness (Markenson et al., 2005; Walsh et al., 2012), disease prevention or health promotion (Coleman et al., 2013; NHS Health Check national competency and training working group, 2014; Healthy People Curriculum Task Force, 2020) and global health (Benzian et al., 2015; Jogerst et al., 2015). To address differing knowledge and skill requirements of professions or roles, several frameworks described levels of required competency attainment (Mantas et al., 2010; Walsh et al., 2012; Benzian et al., 2015; Jogerst et al., 2015) e.g. core, role-specific, disciplinespecific and specialised competencies in disaster medicine and public health (Walsh et al., 2012).

\section{Cultural competency}

Using appropriate knowledge, skills and attitudes to communicate and practise with cultural appropriateness featured strongly. Attributes outlined included a background awareness and understanding of cultural competence principles (Maffeo et al., 2009; Poirier et al., 2009; Woodard et al., 2016; J.R. Covvey \& Ryan, 2018), awareness of the patient as an individual (Jarvis et al., 2004; Johnson \& Traynor, 2018; Diaz-Cruz, 2019) and respect for the values of others (Woodard et al., 2016). Recognition of the health beliefs and assumptions that may influence the behaviours of a health professional (Maffeo et al., 2009; Packard et al., 2010) and the ability to modify self-behaviours were also identified as required competencies (Woodard et al., 2016).

\section{Medicines management and patient care}

Public health skills of importance in this domain related to participation in health promotion and disease prevention activities. The consideration of health literacy in consumers was also highlighted as important for all pharmacy interactions (Poirier et al., 2009; Chen et al., 2013; Coleman et al., 2013; Bryson et al., 2014;
J.R. Covvey \& Ryan, 2018; Vardanyan et al., 2018; Earl et al., 2019).

\section{Health promotion and disease prevention}

A broad range of competencies contributing to health promotion and disease prevention featured in this domain. The understanding and awareness of public health concepts underpinning interventions were described as important (Lee, 2019). Examples included basing activity on the social determinants of health (Dean et al., 2014; Diaz-Cruz, 2019) and community need (Benzian et al., 2015; Kristina et al., 2018), awareness and use of theory to explain behaviour change and readiness for change (Jarvis et al., 2004; Maffeo et al., 2009; Um et al., 2013; Dean et al., 2014), awareness of health behaviours (Maffeo et al., 2009), and using concepts of social learning and educating by empowerment (Saini et al., 2011). Skills in the implementation of programs also featured strongly (Jarvis et al., 2004; Haddad et al., 2012; DiVall et al., 2013; Saini et al., 2011; Kristina et al., 2018) and included providing patient education on lifestyle, disease and education (Patterson, 2008; Saini et al., 2011; Haddad et al., 2012; Um et al., 2013; Scott et al., 2016) using appropriate tools, materials and resources (Um et al., 2013; Dare et al., 2017; Lee, 2019).

The role of community pharmacists in referring or signposting patients to appropriate health or other service providers was discussed (Bryson et al., 2014; Dare et al., 2017; National Institute for Health and Care Excellence, 2018; Holden \& Evans, 2019). Competencies to ensure pharmacists could design appropriate health promotion, prevention or outreach services (DiVall et al., 2013; Lee, 2019) as well as evaluate them (DiVall et al., 2013; Kristina et al., 2018) were also suggested.

Activities and required competencies directed at community approaches, rather than individual patient care, were described by some papers (Haddad et al., 2012; DiVall et al., 2013; Law et al., 2019). These competencies included skills such as the delivery of appropriate outreach health programs to targeted populations (DiVall et al., 2013), dissemination of public health information (Law et al., 2019) and the delivery of health education incorporating disease prevention or medication-relation information to the community (Haddad et al., 2012).

\section{Health literacy}

Competencies in health literacy featured in papers (Poirier et al., 2009; Devraj et al., 2010; Chen et al., 2013; DiVall et al., 2013; Bryson et al., 2014; Earl et al., 2019; Law et al., 2019;) and included identifying the 
literacy levels of patients (Devraj et al., 2010; Earl et al., 2019; Law et al., 2019) using health literacy screening instruments (Devraj et al., 2010; Chen et al., 2013;), and employing appropriate oral or written strategies for people with low health literacy (Devraj et al., 2010; Chen et al., 2013; DiVall et al., 2013; Earl et al., 2019). Assessing written health information for appropriateness in low health literacy (Devraj et al., 2010; Chen et al., 2013; Earl et al., 2019) and being able to create appropriate materials or reduce the readability of health information was also required (Devraj et al., 2010; Chen et al., 2013; DiVall et al., 2013; Earl et al., 2019).

\section{Leadership}

Competencies in this domain included both leadership and management skills (Pfleger et al., 2008; Fox et al., 2011; Crane et al., 2010; Bryson et al., 2014; Benzian et al., 2015; Bradley et al., 2015; Scott et al., 2016; Teng et al., 2016). Managerial skills included program management (Pfleger et al., 2008; Bradley et al., 2015), using pharmacoeconomic modelling and skills for financial management (Bradley et al., 2015; Teng et al., 2016), data management (Fox et al., 2011), managing quality and risk (Pfleger et al., 2008) and being able to evaluate services in order to implement improvement (Bryson et al., 2014; Bradley et al., 2015). In the global health context, the management of health resources was identified as necessary (Benzian et al., 2015). Leadership competencies described included selfassessment of personal skills (Janke et al., 2013; Bradley et al., 2015; Jogerst et al., 2015; Fritsch et al., 2016; Interprofessional Education Collaborative, 2016), flexible and innovative thinking and being able to provide alternative solutions (Crane et al., 2010; Bradley et al., 2015; Scott et al., 2016).

\section{Education and research}

Skills in the education and research domain were described most commonly in the competency frameworks which were broad and comprehensive in nature (Pfleger et al., 2008; Bryson et al., 2014; Benzian et al., 2015; Jogerst et al., 2015; J.R. Covvey \& Ryan, 2018; National Institute for Health and Care Excellence, 2018; Healthy People Curriculum Task Force, 2020). The focus revolved around using information and research to understand and develop practice, as well as the evaluation and monitoring of progress across the implementation of activities (Bryson et al., 2014). Research concepts and skills were recognised as necessary for the provision of services (Rutland \& Smith, 2010; DiPietro et al., 2013; Teng et al., 2016Law et al., 2019; Lee, 2019). Skills to assist in information searching (Rutland \& Smith, 2010) and communication
(Lee, 2019), design and delivery of programs (DiPietro et al., 2013) and service improvement (DiPietro et al., 2013; Law et al., 2019) ultimately contribute to quality services improving patient satisfaction and outcome (DiPietro et al., 2013). The use of data and data systems is also fundamental as a competency in health informatics (Mantas et al., 2010; Fox et al., 2011; Pontefract \& Wilson, 2019). Competency in education and mentoring was addressed from the viewpoint of training other health professionals (Patterson, 2008; Martin et al., 2019) and acting as a mentor or coach (Pfleger et al., 2008).

\section{Discussion}

The results of this scoping review provided a broad overview of the competencies required to enable pharmacists to contribute to public health. The inclusion of 58 studies of differing methodologies provided an overview of the skills, knowledge and attitudes considered by professional organisations, experts and educators as important for pharmacists. Approximately one third of included studies were developed frameworks of competencies, two of which directly addressed pharmaceutical public health competencies (Pfleger et al., 2008; Bryson et al., 2014). Published frameworks provided comprehensive descriptions of competencies considered important in pharmaceutical public health generally, but also in particular areas of this field. The inclusion of 38 papers that used or discussed competencies afforded a richer understanding of the issues considered relevant, particularly in the training and education of pharmacists.

This review highlights the importance of public health knowledge and skills contributing to competencies required by pharmacists to practise effectively within their local communities and health systems. Results across all public health areas of practices confirms the importance of systematically mapping the integration of public health strategies to pharmacy practice. Work published in the UK and the USA is confirmed as examples of the broad applicability of public health areas of practice to pharmacy. Other competency frameworks and papers included give detailed information on particular aspects of practice or examples of application in pharmacist training.

Elements of public health practice should be examined in detail to assist pharmacists to be aware of their role in the health of populations. Examples include using public health's traditional knowledge skills in biostatistics and epidemiology as a basis for pharmacists to identify or develop appropriate health 
programs for communities (Strand \& Miller, 2014). Competency in community engagement and partnership approaches, as well as awareness of health inequities and engagement with vulnerable or underserved people, enable pharmacists to increase the likelihood of positive impacts in population health. Educational programs describing the use of foundational clinical or technical skills in novel public health contexts are examples of ensuring that pharmacy training can move beyond a focus on therapeutics and include skills in putting clinical knowledge into action (Woodard et al., 2018). Important areas for consideration include pharmaceutical public health broadly, as well as considering public health skills in health promotion and disease prevention, interprofessional practice, communication and engagement, and emerging important areas such as global health, health informatics and disaster and emergency response.

\section{Pharmaceutical public health}

Competencies or standards directly addressing pharmacy and public health were examined by several papers (Pfleger et al., 2008; Bryson et al., 2014; Strand $\&$ Miller, 2014). The development of the earliest pharmaceutical public health competency framework was published in 2008 for community pharmacists in Scotland. Participants in this study considered that some areas of public health practice such as surveillance and policy were not applicable to community pharmacy (Pfleger et al., 2008). However, in contrast, a UK standard published six years later considered that all public health competency areas were applicable to pharmacists, irrespective of practice setting (Bryson et al., 2014). This was consistent with views from the USA that all areas of public health practice are consistent with pharmacy roles (Strand \& Miller, 2014). Examples outlined in these papers are illustrations of how pharmacists can apply public health in practice (Bryson et al., 2014; Strand \& Miller, 2014).

\section{Health promotion, screening and disease prevention}

Competencies around the provision of health promotion and disease prevention featured strongly. This is consistent with the inclusion of health promotion in the role of pharmacists over recent decades (S. Anderson, 2007; Todd, 1993). Papers recommended that health professionals have skills across all programs including the development, implementation and evaluation of activities (Haddad et al., 2012; DiVall et al., 2013; Bryson et al., 2014; Kristina et al., 2018). The support of public health programs by pharmacists should include the awareness of the impacts of social determinants of health and the use of effective models for interventions in health screening, disease prevention and health promotion (Jarvis et al., 2004; Maffeo et al., 2009; Mantas et al., 2010; DiVall et al., 2013; Bryson et al., 2014; Dean et al., 2014; Benzian et al., 2015; Jogerst et al., 2015; Fritsch et al., 2016; J. R. Covvey \& Ryan, 2018; Johnson \& Traynor, 2018; DiazCruz, 2019; Law et al., 2019; Healthy People Curriculum Task Force, 2020).

\section{Emerging pharmacy roles}

Emerging roles for pharmacists to incorporate into practice include global health (Benzian et al., 2015; Jogerst et al., 2015; J. R. Covvey \& Ryan, 2018), health informatics (Mantas et al., 2010; Fox et al., 2011; Martin et al., 2019; Pontefract \& Wilson, 2019) and disaster or emergency response (Markenson et al., 2005; Crane et al., 2010; Abraham et al., 2012; Walsh et al., 2012; Hannings et al., 2016; International Pharmaceutical Federation, 2016; Kim et al., 2017).

\section{Global health}

The production of global health competency statements over the last five years illustrates the importance now placed on this field of public health (Benzian et al., 2015; Jogerst et al., 2015; J. R. Covvey \& Ryan, 2018). Global health training enables pharmacists and other health professionals to be prepared for roles abroad, but also increases skills in practising from a public health perspective, with cultural appropriateness, and to underserved populations (Benzian et al., 2015; Jogerst et al., 2015J. R. Covvey \& Ryan, 2018).

\section{Health Informatics}

Health informatics and the related area of working in digital environments are areas in which pharmacists, along with other health professionals, must participate. Basic skills in health informatics allows pharmacists to be able to appropriately access, store and use patient data to inform their practice, as well as practise safely and effectively within a health care team (Mantas et al., 2010; Fox et al., 2011; Martin et al., 2019; Pontefract \& Wilson, 2019).

\section{Disaster and emergency response}

Disaster or emergency preparedness is an evolving area for pharmacy practice and development (McCourt, Singleton, Tippett, \& Nissen, 2020) and is currently a prominent topic, give the spread of COVID-19 across the globe (Watson et al., 2021). Skills across a range of pharmacy competency domains including communication (Mantas et al., 2010; Abraham et al., 2012; International Pharmaceutical Federation, 2016; 
Kim et al., 2017), awareness of legal and ethical considerations in response (Abraham et al., 2012; International Pharmaceutical Federation, 2016), resource and personnel management (Crane et al., 2010; International Pharmaceutical Federation, 2016), as well as the application of clinical skills in unique environments were identified (Crane et al., 2010). An underlying tenet of disease or emergency response is for health professionals to be aware of the scope of practice of their own roles (Crane et al., 2010; Hannings et al., 2016; Kim et al., 2017). Emergency preparedness was outlined as operating from the individual, health service and community levels, with pharmacists having responsibilities and roles at all levels (International Pharmaceutical Federation, 2016; Kim et al., 2017).

\section{Professional attributes and interprofessional practice}

The framework mapping of competencies showed a strong representation within the professional practice areas of both pharmacy and public health (Figures 2 and 3). This illustrates the importance of underlying knowledge and attributes on which to base clinical skills related to pharmacy and health interventions. Professional competencies allow the pharmacist to practise ethically, legally and cross-culturally (Pfleger et al., 2008; Saini et al., 2011; Walsh et al., 2012; NHS Health Check national competency and training working group, 2014; Benzian et al., 2015; Jogerst et al., 2015; Fritsch et al., 2016; Interprofessional Education Collaborative, 2016; Woodard et al., 2016; J. R. Covvey \& Ryan, 2018; Kim et al., 2017; Johnson \& Traynor, 2018; Pontefract \& Wilson, 2019), recognise professional and personal strengths or weaknesses (Janke et al., 2013; Jogerst et al., 2015; Bradley et al., 2015; Fritsch et al., 2016; Interprofessional Education Collaborative, 2016) and understand their role in health care and the community (Crane et al., 2010; Bzowyckyj \& Janke, 2013; Abraham et al., 2012; Walsh et al., 2012; Bradley et al., 2015; Hannings et al., 2016; Interprofessional Education Collaborative, 2016; J. R. Covvey \& Ryan, 2018; Healthy People Curriculum Task Force, 2020).

Competency in the professional aspects of a health discipline is consistent with being able to work effectively with other professionals. Half of the included competency frameworks in this review were based on competencies for a range of health professions (Markenson et al., 2005; Mantas et al., 2010; Walsh et al., 2012; Coleman et al., 2013; Benzian et al., 2015; NHS Health Check national competency and training working group, 2014; Jogerst et al., 2015; Interprofessional Education Collaborative, 2016; Pontefract \& Wilson, 2019; Healthy People Curriculum Task Force, 2020), underpinning the premise that public health approaches across all disciplines are required. Collaboration amongst the health care team was identified as integral to addressing public health indicators (Patterson, 2008; Pfleger et al., 2008; McCaig et al., 2011; Saini et al., 2011; Abraham et al., 2012; Haddad et al., 2012; Janke et al., 2013; Um et al., 2013; Bryson et al., 2014; NHS Health Check national competency and training working group, 2014; Benzian et al., 2015; Bradley et al., 2015; Jogerst et al., 2015; Fritsch et al., 2016; Interprofessional Education Collaborative, 2016; Scott et al., 2016; Dare et al., 2017; Kim et al., 2017; Kristina et al., 2018; Holden \& Evans, 2019; Healthy People Curriculum Task Force, 2020), with communication as the basis for respectful contributions from all professions.

\section{Communication and engagement}

Excellence in communication skills was identified as important to a wide range of activities required to address public health. Effective communication is based on psychological and behavioural theory (Maffeo et al., 2009; Saini et al., 2011; Dean et al., 2014; Lee, 2019) and the incorporation of appropriate strategies and techniques to encourage outcomes such as positive behaviour change (Jarvis et al., 2004; Pfleger et al., 2008; Maffeo et al., 2009; McCaig et al., 2011; Um et al., 2013; Bryson et al., 2014; Dean et al., 2014; Bradley et al., 2015; Woodard et al., 2016Healthy People Curriculum Task Force, 2020; Johnson \& Traynor, 2018; Holden \& Evans, 2019; Law et al., 2019). This is vital to the implementation of interventions in health promotion, disease screening and prevention. Communication was additionally seen as a base for engagement on a wider level across professions and communities (Pfleger et al., 2008; Bryson et al., 2014; Jogerst et al., 2015; Interprofessional Education Collaborative, 2016) as activities suggested as necessary for ensuring impact beyond individual care (Anderson \& Wang, 2016).

\section{Strengths and limitations}

Limitations of the review included the restriction to English-only studies. Additionally, terminology used to describe public health and related services e.g. health promotion or health education, is often used interchangeably and interpretation may differ between countries and published literature. Differing interpretations of terms may also have affected the extraction of competencies into public health and pharmacy domains. However, the matrix charting of data was intended to give a broad understanding of the content of published literature.

Papers primarily originated from the USA and UK. The reliance on literature from a small number of countries may limit the diversity of knowledge and approaches in 
this topic; however, it is indicative of the health policies and development of pharmacy involvement in public health in these countries (American Public Health Association, 2006; Root \& Vaney, 2017). The review purposely did not include studies primarily focussed on a service offered by a pharmacy or pharmacist in specific clinical areas unless there was discussion of non-therapeutic skills or competencies required. Studies discussing pharmacy roles and services in clinical areas comprise the majority of the literature pertaining to pharmaceutical public health and have been the topic of other reviews (Agomo et al., 2018; Buss et al., 2018).

\section{Conclusion}

This review was intended to be a broad synthesis of knowledge, skills and attributes that may be important for pharmacists to contribute to modern health systems in the area of pharmaceutical public health. It aimed to describe competencies required by pharmacists and was conducted from the perspective of the Australian health setting.

Competencies in public health were found to be relevant for pharmacists practising in a range of settings. A public health perspective in all pharmacy competency domains assists pharmacists to understand their responsibility to improving the health and wellbeing of communities and populations. A basic level of knowledge and skills considered as public health is required for pharmacists to deliver effective health programs and responsibilities that support and enhance their central role as medication experts. The incorporation of underlying skills traditionally regarded as public health in health screening, health promotion and disease prevention incorporated into the skill sets of pharmacists would be of benefit. This is consistent with international moves to ensure health professionals work as a team and engage with the communities in which they practise. Additionally, the adaptation of health professional roles in line with societal change will require the ongoing evolvement of the ability of pharmacists to appropriately participate in areas such as disaster and emergency response, global health and digital health. The requirement for many of these skills to apply to any health professional will see a basic level of competency across all disciplines increase in importance.

The inclusion of public health competencies into undergraduate training and professional development is important to ensure that pharmacists are aware of their responsibilities on a community or population level. Internationally, the extent to which this is currently available is variable. However, world events, such as natural disasters and the emergence of COVID19 , have highlighted the need that pharmacists are able to respond to public health demands.

This review serves as a first step to engaging with stakeholders, including public health and pharmacy experts, pharmacy academics and educators, and practising pharmacists, to discuss their perspectives on review results, in accordance with their experience (Levac, Colquhuon, \& O'Brien, 2010). The findings may serve as a base on which to assess competencies for the pharmacy profession and inform the development of professional curricula in pharmaceutical public health in Australia and other countries in which alignment between pharmacy and public health has not been undertaken. Consideration of core public health skills as attributes for pharmacists enable the effective delivery of health care and ensures that the practice of the profession benefits local, national and global health indicators and achieves development of the profession.

\section{References}

American Academy of Family Physicians, Integration of Primary Care and Public Health Work Group. (2015). Integration of Primary Care and Public Health (Position Paper). Available at:

https://www.aafp.org/about/policies/all/integprimarycarea ndpublichealth.html

Abraham, R.T., Walls, R.T., Fischer, M., Markovic-Reed, S., Solovieva, T.I., Russell, F.K., \& Ducatman, A.M. (2012). Tabletop scenarios for realism in bioterrorism and threat preparedness. West Virginia Medical Journal, 108(6), 12-17

Addo-Atuah, J. (2014). Making a case for a public health orientation in global pharmacy education and practice in the context of the Millenium Development Goals (MDGs). Currents in Pharmacy Teaching and Learning, 6, 723-729. https://doi.org/10.1016/j.cptl.2014.05.019

Agomo, C., Udoh, A., Kpokiri, E., \& Osuku-Opio, J. (2018). Community pharmacists' contribution to public health: assessing the global evidence base. The Pharmaceutical Journal Clinical Pharmacists, 10(4).

https://doi.org/10.1211/CP.2018.20204556

American Public Health Association. (2006). The Role of the Pharmacist in Public Health. Available at:

https://www.apha.org/policies-and-advocacy/public-healthpolicy-statements/policy-database/2014/07/07/13/05/therole-of-the-pharmacist-in-public-health

Anderson, L., \& Wang, L.-N. (2016). Stepping Forward. International Pharmacy Journal, 34(1), 3. Available at: https://www.fip.org/www/streamfile.php?filename=fip/IPJ/ IPJ_341_FINAL.compressed.pdf

Anderson, S. (2007). Community pharmacy and public health in Great Britain, 1936 to 2006: how a phoenix rose from the 
ashes. Journal of Epidemiology and Community Health, 61(10), 844-848. https://doi.org/10.1136/jech.2006.055442

Arksey, H., \& O'Malley, L. (2005). Scoping studies: Towards a Methodological Framework. International Journal of Social Research Methodology, 8(1), 19-32. https://doi.org/10.1080/1364557032000119616

Austin, Z. (2020). What just happened (and keeps on happening)?: The experience of COVID-19 in Canadian pharmacy practice and education. Pharmacy Education, 2, 110-113. https://doi.org/10.46542/pe.2020.202.110113

Benzian, H., Greenspan, J.S., Barrow, J., Hutter, J.W., Loomer, P.M., Stauf, N., \& Perry, D.A. (2015). A competency matrix for global oral health. Journal of Dental Education, 79(4), 353-361. https://doi.org/10.1002/j.00220337.2015.79.4.tb05891.x

Boyle, C.J., Beardsley, R.S., \& Hayes, M. (2004). Effective leadership and advocacy: Amplifying professional citizenship. American Journal of Pharmaceutical Education, 68(3), 1-5. https://doi.org/10.5688/aj680363

Bradley, H., Lehmann, U., \& Butler, N. (2015). Emerging roles and competencies of district and sub-district pharmacists: a case study from Cape Town. Human Resources for Health [Electronic Resource], 13, 88.

https://doi.org/10.1186/s12960-015-0081-8

Bryson, S., Cox, C., Davison, H., Edmondson-Jones, P., Harris, F., Hinchliffe, A., Mathew, S., Oza, P., Parish, R., Radley, A., Root, G., Scott-Clark, A., Soni, A. (2014). Professional Standards for Public Health Practice for Pharmacy. Available at: https://www.patientlibrary.net/cgi-

bin/downloadhw.cgi?file=824;gen=zh3P6He21Uc9du0|ZrJV M@NLLsYmR6ZlecEkRyRE8E7T2S3vxY

Buss, V.H., Shield, A., Kosari, S., \& Naunton, M. (2018). The impact of clinical service provided by community pharmacies on the Australian healthcare system: a review of the literature. Journal of Pharmaceutical Policy and Practice, 11(22). http://doi.org/10.1186/s40545-018-0149-7

Bzowyckyj, A.S., \& Janke, K.K. (2013). A Consensus Definition and Core Competencies for Being an Advocate for Pharmacy. American Journal of Pharmaceutical Education, 77(2), Article 24. https://doi.org/10.5688/ajpe77224

Chen, A.M., Noureldin, M., \& Plake, K. (2013). Impact of a health literacy assignment on student pharmacist learning. Research in Social and Administrative Pharmacy, 9, 531-541. https://doi.org/10.1016/j.sapharm.2013.05.002

Coleman, C.A., Hudson, S., \& Maine, L.L. (2013). Health Literacy Practices and Educational Competencies for Health Professionals: A Consensus Study. Journal of Health Communication, 18(Supp 1), 82-102.

https://doi.org/10.1080/10810730.2013.829538

Genat, B., Robinson, P., Parker, E. (2016). Foundation Competencies for Public Health Graduates in Australia. In S. Somerset, P. Robinson, \& H. Kelsall (Eds). Council of Academic Public Health Institutions Australia. Available at: http://caphia.com.au/testsite/wpcontent/uploads/2016/07/CAPHIA_document_DIGITAL_nov _22.pdf
Covvey, J.R., Conry, J.M., Bullock, K.C., diPietro Mager, N.A., Goad, J., Golchin, N., Patel, R.V., Strand, A.M., Truong, H., Abrons, P.J., Venci, P.D., Patterson-Browning, B. (2016). Public Health and the CAPE 2013 Educational Outcomes: Inclusion, Pedagogical Considerations and Assessments. Available at: http://aacp.org/sites/default/files/201710/PublicHealthSIGCAPEpaper.pdf

Covvey, J.R., \& Ryan, M. (2018). Use of a Modified Delphi Process to Determine Course Objectives for a Model Global Health Course in a Pharmacy Curriculum. American Journal of Pharmaceutical Education, 82(8), 6358. https://doi.org/10.5688/ajpe6358

Crane, J.S., McCluskey, J.D., Johnson, G.T., \& Harbison, R.D. (2010). Assessment of community healthcare providers ability and willingness to respond to emergencies resulting from bioterrorist attacks. Journal of Emergencies, Trauma and Shock, 3(1), 13-20. https://doi.org/10.4103/09742700.55808

Dare, J., Wilkinson, C., Garlepp, M., Lo, J., \& Allsop, S. (2017). Community pharmacists require additional support to develop capacity in delivering alcohol-related health information to older adults. International Journal of Pharmacy Practice, 25(4), 301-310.

https://doi.org/10.1111/ijpp.12319

Dean, E., Moffat, M., Skinner, M., de Andrade, A.D., Myezwa, H., \& Soderlund, A. (2014). Toward core interprofessional health promotion competencies to address the non-communicable diseases and their risk factors through knowledge translation: Curriculum content assessment. BMC Public Health, 14, 717. https://doi.org/10.1186/14712458-14-717

Devraj, R., Butler, L.M., Gupchup, G.V., \& Poirier, T.I. (2010). Active-learning strategies to develop health literacy knowledge and skills. American Journal of Pharmaceutical Education, 74(8). https://doi.org/10.5688/aj7408137

Diaz-Cruz, E.S. (2019). If cultural sensitivity is not enough to reduce health disparities, what will pharmacy education do next? Currents in Pharmacy Teaching and Learning, 11(5), 538-540. https://doi.org/10.1016/j.cptl.2019.02.003

Dineen-Griffin, S., Benrimoj, S.I., \& Garcia-Cardenas, V. (2020). Primary health care policy and vision for community pharmacy and pharmacists in Australi. Pharmacy Practice (1886-3655), 18(2), 1967.

https://doi.org/10.18549/PharmPract.2020.2.1967

DiPietro, N.A., Rush, M.J., Bright, D.R., Kroustos, K.R., \& Milks, M.M. (2013). Strategies to engage pharmacy students and residents in worksite-based health and wellness programs. Currents in Pharmacy Teaching and Learning, 5(1), 68-74. https://doi.org/10.1016/j.cptl.2012.09.008

DiVall, M.V., Edwards, R.A., Stevens, C.A., Zilberman, E., Watanabe, M.D., \& Kirwin, J.L. (2013). Student perceptions about developing an evidence-based public health program directed toward a vulnerable population. Currents in Pharmacy Teaching and Learning, 5(2), 76-84. https://doi.org/10.1016/j.cptl.2012.09.004

Eades, C.E., Ferguson, J.S., \& O'Carroll, R.E. (2011). Public health in community pharmacy: A systematic review of pharmacist and consumer views. BMC Public Health, 11, 582. https://doi.org/10.1186/1471-2458-11-582 
Earl, G.L., Harris, E.M., Dave, M., \& Estriplet-Jiang, J. (2019). Implementing a health literacy module fostering patientcentered written communication in a cardiovascular prevention elective course. Currents in Pharmacy Teaching and Learning, 11(7), 702-709.

https://doi.org/10.1016/j.cptl.2019.03.008

Fleming, M.L., \& Parker, E. (2015). Introduction to Public Health (3 ed.). Chatswood NSW: Elsevier

Fox, B.I., Flynn, A.J., Fortier, C.R., \& Clauson, K.A. (2011). Knowledge, Skills and Resources for Pharmacy Informatics Education. American Journal of Pharmaceutical Education, 75(5), Article 93. https://doi.org/10.5688/ajpe75593

Frenk, J., Chen, L., Bhutta, Z.A., Cohen, J., Crisp, N., Evans, T., Fineberg, H., Garcia, P., Ke, Y., Kelley, P., Kistnasamy, B., Meleis, A., Naylor, D., Pablos-Mendez, A., Reddy, S., Scrimshaw, S., Sepulveda, J., Serwadda, D., \& Zurayk, H. (2010). Health Professionals for a new century: transforming education to strengthen health systems in an interdependent world. Lancet, 376, 1923-1958. https://doi.org/10.1016/S0140-6736(10)61854-5

Fritsch, M.A., Culver, N., Culhane, N., Thigpen, J., \& Lin, A. (2016). AdvoCaring: A Cocurricular Program to Provide Advocacy and Caring to Underserved Populations in Baltimore. American Journal of Pharmaceutical Education, 80(7), 126. https://doi.org/10.5688/ajpe807126

Godin, K., Stapleton, J., Kirkpatrick, S.I., Hanning, R.M., \& Leatherdale, S.T. (2015). Applying systematic review search methods to the grey literature: a case study examining guidelines for school-based breakfast programs in Canada. Systematic Reviews, 4(138).

https://doi.org/10.1186/s13643-015-0125-0

Haddad, A. M. R., Coover, K. L., Begley, K. J., \& Tilleman, J. A. (2012). An advanced pharmacy practice experience in community engagement. American Journal of Pharmaceutical Education, 76(5).

https://doi.org/10.5688/ajpe76590

Hager, K.D., Blue, H.L., Zhang, L., \& Palombi, L.C. (2019). Opoids: cultivating interprofessional collaboration to find solutions to public health problems. Journal of Interprofessional Care, 33(1), 120-124.

https://doi.org/10.1080/13561820.2018.1516634

Hannings, A.N., von Waldner, T., McEwen, D.W., \& White, C.A. (2016). Assessment of Emergency Preparedness Modules in Introductory Pharmacy Practice Experiences. American Journal of Pharmaceutical Education, 80(2), 23. https://doi.org/10.5688/ajpe80223

Healthy People Curriculum Task Force. (2020). Clinical Prevention and Population Health Curriculum Framework. Available at: https://www.teachpopulationhealth.org

Holden, M., \& Evans, D. (2019). Healthy Living Pharmacy knowledge into action. Perspectives in Public Health, 139(1), 13-14. https://doi.org/10.1177/1757913918815425

International Pharmaceutical Federation. (2012). Pharmacy Education Taskforce. A Global Competency Framework. Version 1. Available at:

https://www.fip.org/files/fip/PharmacyEducation/GbCF_v1. pdf
International Pharmaceutical Federation. (2016).

Responding to disasters: Guidelines for pharmacy 2016. In. The Netherlands: International Pharmaceutical Federation.

International Pharmaceutical Federation. (2020a). The FIP Development Goals: Transforming global pharmacy. The Hague, The Netherlands. Available at: https://www.fip.org/file/4793

International Pharmaceutical Federation. (2020b). FIP Global Competency Framework: Supporting the development of foundation and early career pharmacists. The Hague, The Netherlands. Available at: https://www.fip.org/file/4805

Interprofessional Education Collaborative. (2016). Core Competencies for Interprofessional Collaborative Practice: 2016 Update. Available at:

https://hsc.unm.edu/ipe/resources/ipec-2016-corecompetencies.pdf

Janke, K.K., Traynor, A.P., \& Boyle, C. (2013). Competencies for Student Leadership Development in Doctor of Pharmacy Curricula to Assist Curriculum Committees and Leadership Instructors. American Journal of Pharmaceutical Education, 77(10), Article 222. https://doi.org/10.5688/ajpe771022

Jarvis, C., James, V.L., Giles, J., \& Turner, C.J. (2004). Nutrition and nurturing: A service-learning nutrition pharmacy course. American Journal of Pharmaceutical Education, 68(2), 1-8. https://doi.org/10.5688/aj680126

Joanna Briggs Institute. (2015). The Joanna Briggs Institute Reviewers' Manual 2015. Methodology for JBI Scoping Reviews. Available at: http://joannabriggs.org/assets/docs/sumari/ReviewersManual_Methodology-for-JBI-Scoping-Reviews_2015_v2.pdf

Joanna Briggs Institute, \& University of Adelaide. (2013). JBI Levels of Evidence. Available at:

https://joannabriggs.org/sites/default/files/2019-05/JBILevels-of-evidence_2014_0.pdf

Jogerst, K., Callender, B., Adams, V., Evert, J., Fields, E., Hall, T., Olsen, J., Rowthorn, V., Rudy, S., Shen, J., Simon, L., Torres, H., Velji, A., \& Wilson, L.L. (2015). Identifying Interprofessional Global Health Competencies for 21stCentury Health Professionals. Annals of Global Health, 81(2), 239-247. https://doi.org/10.1016/j.aogh.2015.03.006

Johnson, C., \& Traynor, A.P. (2018). Idetnifying student learning competencies for urban underserved practice using a Delphi process. Currents in Pharmacy Teaching \& Learning, 10, 87-694.

https://doi.org/10.1016/j.cptl.2018.03.007

Kim, T.E., Shankel, T., Reibling, E.T., Paik, J., Wright, D., Buckman, M., Wild, K., Ngo, E., Hayatshahi, A., Nguyen, L.H., Denmark, T.K., \& Thomas, T. L. (2017). Healthcare students interprofessional critical event/disaster response course. American Journal of Disaster Medicine, 12(1), 11-26. https://doi.org/10.5055/ajdm.2017.0254

King, A.E., \& Egras, A.M. (2015). A Required Online Course with a Public Health Focus for Third Professional Year Pharmacy Students. American Journal of Pharmaceutical Education, 79(5), 68. https://doi.org/10.5688/ajpe79568 
Koplan, J.P., Bond, T.C., Merson, M.H., Reddy, K.S. Rodriguez, M.H., Sewankambo, N.K., \& Wasserheit, J.N. (2009). Towards a common definition of global health. Lancet, 373, 1993-1995. https://doi.org./10.1016/S01406736(09)60332-9

Kristina, S.A., Yulianto, Y., \& Prabandari, Y.S. (2018). Early experience with a health promotion course for pharmacy students in Indonesia. Health Education Journal, 77(2), 241248. https://doi.org./10.1177/0017896917732362

Law, M.G., Maposa, P., Chambula, E., Steeb, D.R., Eckel, S.F., \& Duncan, G. (2019). Knowledge, attitudes and practice of final-year student pharmacists in public health in Namibia, Zambia and Zimbabwe: an exploratory survey. International Journal of Pharmacy Practice, 27(1), 55-62. https://doi.org/10.1111/ijpp.12460

Lee, S.W.H. (2019). Pharmacy student-led health education campaign initiative. Currents in Pharmacy Teaching and Learning. https://doi.org/10.1016/j.cptl.2018.12.010

Levac, D., Colquhuon, H., \& O'Brien, K.K. (2010). Scoping studies: advancing the methodology. Implementation Science, 5, 69. https://doi.org/10.1186/1748-5908-5-69

Levesque, J.-F., Breton, M., Senn, N., Levesque, P., Bergeron, P., \& Roy, D.A. (2013). The Interaction of Public Health and Primary Care: Functional Roles and Organizational Models that Bridge Individual and Population Perspectives. Public Health Reviews, 35(1). https://doi.org/10.1007/BF03391699

Little, J., Ortega, M., Powell, M., \& Hamm, M. (2019). ASHP Statement on Advocacy as a Professional Obligation. American Journal of Health-System Pharmacy, 76(4), 251253. https://doi.org/10.1093/ajhp/zxy040

Lomazzi, M. (2016). A Global Charter for the Public's Healththe public health system: role, functions, competencies and education requirements. European Journal of Public Health, 26(2), 210-212. https://doi.org/10.1093/eurpub/ckw011

Maffeo, C., Chase, P., Brown, B., Tuohy, K., \& Kalsekar, I. (2009). My first patient program to introduce first-year pharmacy students to health promotion and disease prevention. American Journal of Pharmaceutical Education, 73(6). https://doi.org/10.5688/aj730697

Mantas, J., Ammenwerth, E., Demiris, G., Hasman, A., Haux, R., Hersh, W., Hovenga, E., Lun, K.C., Marin, H., MartinSanchez, F., Wright, G. (2010). Recommendations of the international medical informatics association (IMIA) on education in biomedical and health informatics. Methods of Information in Medicine, 49(2), 105-120.

https://doi.org/10.3414/ME5119

Markenson, D., DiMaggio, C., \& Redlener, I. (2005). Preparing Health Professions Students for Terrorism, Disaster, and Public Health Emergencies: Core Competencies. Academic Medicine, 80(6), 517-526. https://doi.org/10.1097/00001888-200506000-00002

Martin, L.G., Warholak, T.L., Hincapie, A.L., Gallo, T., Kjos, A. L., \& AACP Joint Task Force on Informatics. (2019). Health Informatics Competencies for Pharmacists in Training. American Journal of Pharmaceutical Education, 83(2), 6512. https://doi.org/10.5688/ajpe6512
McCaig, D., Fitzgerald, N., \& Stewart, D. (2011). Provision of advice on alcohol use in community pharmacy: a crosssectional survey of pharmacists' practice, knowledge, views and confidence. International Journal of Pharmacy Practice, 19(3), 171-178. https://doi.org/10.1111/j.2042-

7174.2011.00111.x

McCourt, E., Singleton, J.A., Tippett, V., \& Nissen, L. (2020). Disaster preparedness amongst pharmacists and pharmacy students: a systematic literature review. International Journal of Pharmacy Practice. https://doi.org/10.1111/ijpp.12669

Meyerson, B.E., Ryder, P.T., \& Richey-Smith, C. (2013). Achieving Pharmacy-Based Public Health: A Call for Public Health Engagement. Public Health Reports, 128(3), 140-143. https://doi.org/10.1177/003335491312800303

Moher, D., Liberati, A., Tetzlaff, J., Altman., D.G. \& The PRISMA Group. (2009). Preferred Reporting Items for Systematic Review and Meta-Analyses: The PRISMA Statement. PLoS Medicine, 6(7): e1000097. https://doi.org/10.1371/journal.pmed1000097

Munn, Z., Peters, M.D., Stern, C., Tufanaru, C., McArthur, A., \& Aromataris, E. (2018). Systematic review or scoping review? Guidance for authors when choosing between a systematic or scoping review approach. BMC Medical Research Methodology, 18(143). https://doi.org/10.1186/s12874-018-0611-x

National Institute for Health and Care Excellence. (2018). Community pharmacies: promoting health and wellbeing . Available at: https://www.nice.org.uk/guidance/ng102

Nemire, R.E., Ward, C.T., Whalen, K., Quinn, J., Subramaniam, V., Gershon, S.K., \& Zavod, R.M. (2010). Public health matters: the role of the pharmacist and the academy. Currents in Pharmacy Teaching and Learning, 2, 211. https://doi.org/10.1016/j.cptl.2009.12.001

NHS Health Check national competency and training working group. (2014). NHS Health Check competence framework. Available at:

https://www.healthcheck.nhs.uk/commissioners-andproviders/training/competence-framework-supportingworkbooks/

Nichols-English, G.J., White, C.A., \& Brooks, P.J. (2002). Bridging community based pharmacy outreach with servicelearning principles. American Journal of Pharmaceutical Education, 66(2), 124-131

Packard, K., Sexson, E., Spangler, M., \& Walters, R. (2010). A novel cardiovascular risk screening and health promotion service learning course. Currents in Pharmacy Teaching and Learning, 2(4), 228-237. https://doi.org/10.1016/j.cptl.2010.07.001

Palombi, L., Kading, M., \& Hayes, C.J. (2013). The public health pharmacist and the role of the pharmacy curriculum: A call to action. Currents in Pharmacy Teaching and Learning, 5, 477-482. https://doi.org/10.1016/j.cptl.2013.06.011

Patterson, B.Y. (2008). An advanced pharmacy practice experience in public health. American Journal of Pharmaceutical Education, 72(5), 125. https://doi.org/10.5688/aj7205125 
Pfleger, D.E., McHattie, L.W., Diack, H.L., McCaig, D.J., \& Stewart, D.C. (2008). Developing consensus around the pharmaceutical public health competencies for community pharmacists in Scotland. Pharmacy world and science, 30, 111-119. https://doi.org/10.1007/s11096-007-9153-8

Pharmaceutical Society of Australia. (2016). National Competency Standards Framework for Pharmacists in Australia. Available at: https://www.psa.org.au/wpcontent/uploads/2018/06/National-Competency-StandardsFramework-for-Pharmacists-in-Australia-2016-PDF-2mb.pdf

Pharmaceutical Society of Australia. (2018). Pharmacists in 2023: A Discussion Paper. Available at:

https://www.psa.org.au/advocacy/working-for-ourprofession/pharmacists-in-2023/

Poirier, T.I., Butler, L.M., Devraj, R., Gupchup, G.V., Santanello, C., \& Lynch, J.C. (2009). A cultural competency course for pharmacy students. American Journal of Pharmaceutical Education, 73(5).

https://doi.org/10.5688/aj730581

Pontefract, S.K., \& Wilson, K. (2019). Using electronic patient records: Defining learning outcomes for undergraduate education 13 Education 1303 Specialist Studies in Education 11 Medical and Health Sciences 1117 Public Health and Health Services. BMC Medical Education, 19(1). https://doi.org/10.1186/s12909-019-1466-5

Root, G., \& Vaney, J. (2017). Pharmacy: A Way Forward for Public Health. Opportunities for action through pharmacy for public health. London: Public Health England. Available at:

https://assets.publishing.service.gov.uk/government/uploa ds/system/uploads/attachment_data/file/643520/Pharmac y_a_way_forward_for_public_health.pdf.

Roux, A.V.D. (2016). On the Distinction - or Lack of Distinction - Between Population Health and Public Health. American Journal of Public Health, 106(4), 619-620. https://doi.org/10.2105/AJPH.2016.303097

Rutland, J.D., \& Smith, A.M. (2010). Information needs of the 'frontline' public health workforce. Public Health, 124(11), 659-663.

https://doi.org/10.1016/j.puhe.2010.06.002

Saini, B., Shah, S., Kearey, P., Bosnic-Anticevich, S., Grootjans, J., \& Armour, C. (2011). Instructional design and assessment: An interprofessional learning module on asthma health promotion. American Journal of Pharmaceutical Education, 75(2).

https://doi.org/10.5688/ajpe75230

Scott, D.M., Strand, M., Undem, T., Anderson, G., Clarens, A., \& Xiyuan, L.I.U. (2016). Assessment of pharmacists' delivery of public health services in rural and urban areas in lowa and North Dakota. Pharmacy Practice (1886-3655), 14(4), 1-11. https://doi.org/10.18549/PharmPract.2016.04.836

Strand, M.A., Davidson, K.M., \& Schulze, N. (2017). Linking pharmacists to the delivery of public health services. Journal of the American Pharmacists Association, 2017. https://doi.org/10.1016/j.japh.2017.08.011
Strand, M.A., \& Miller, D.A. (2014). Pharmacy and public health: A pathway forward. Journal of the American Pharmacists Association, 54, e220-e224. https://doi.org/10.1331/JAPhA.2014.13145

Teng, M., Khoo, A.L., Zhao, Y.J., Lin, L., \& Lim, B.P. (2016). Integrating health technology assessment principles in formulary management. International Journal of Technology Assessment in Health Care, 32(1-2), 81-87. https://doi.org/10.1017/S0266462316000040

Thomson, K., Hillier-Brown, F., Walton, N., Bilaj, M., Bambra, C., \& Todd, A. (2019). The effects of community pharmacydelivered public health interventions on population health and health inequalities: A review of reviews. Preventive Medicine, 124, 98-109.

https://doi.org/10.1016/j.ypmed.2019.04.003

Todd, J. (1993). The High Street Health Scheme: promoting health in the community pharmacy. Health Education Journal, 52(1), 34-36.

https://doi.org/10.1177/001789699305200107

Tricco, A.C., Lillie, E., Zarin, W., O'Brien, K.K., Colquhoun, H., Levac, D., Moher, D., Peters, M.D.J., Horsley, T., Weeks, L., Hempel, S., Akl, E.A., Chang, C., McGowan, J., Stewart, L., Hartling, L., Aldcroft, A., Wilson, M.G., Garritty, C., Lewin, S., Godfrey, C.M., Macdonald, M.T., Langlois, E.V., SoaresWeiser, K., Moriarty, J., Clifford, T., Tunçalp, Ö., Straus, S.E. (2018). PRISMA Extension for Scoping Reviews (PRISMAScR): Checklist and Explanation. Annals of Internal Medicine, 169, 467-473. https://doi.org/10.7326/M18-0850

Um, I.S., Armour, C., Krass, I., Gill, T., \& Chaar, B.B. (2013). Weight management in community pharmacy: What do the experts think? International Journal of Clinical Pharmacy, 35(3), 447-454. https://doi.org/10.1007/s11096-013-9761-4

Vardanyan, H., Mosegui, G.B. G., \& Miranda, E.S. (2018). Skills and Core Competencies of Pharmacists in Humanitarian Assistance. Prehospital and Disaster Medicine, 33(3). https://doi.org/10.1017/S1049023X18000304

Walsh, L., Subbarao, I., Gebbie, K., Schor, K.W., Lysznicki, J., Strauss-Riggs, K., Cooper, A., Hsu, E.B., King, R.V., Mitas, J.A., 2nd, Hick, J., Zukowski, R., Altman, B.A., Steinbrecher, R.A., \& James, J.J. (2012). Core Competencies for Disaster Medicine and Public Health. Disaster Med Public Health Preparedness, 6, 44-52. https://doi.org/10.1001/dmp.2012.4

Watson, K.E., Schindel, T.J., Barsoum, M.E., \& Kung, J.Y. (2021). COVID the Catalyst for Evolving Professional Role Identity? A Scoping Review of Global Pharmacists' Roles and Services as a Response to the COVID-19 Pandemic. Pharmacy, 9, 99.

https://doi.org/10.3390/pharmacy9020099

Wenger, L.M., Rosenthal, M., Sharpe, J.P., \& Waite, N. (2016). Confronting inequities: A scoping review of the literature on pharmacist practice and health-related disparities. Research in Social and Administrative Pharmacy, 12, 175-217.

https://doi.org/10.1016/j.sapharm.2015.05.011

Woodard, L.J., Kahaleh, A.A., Nash, J.D., Truong, H., Gogineni, H., \& Barbosa-Leiker, C. (2018). Healthy People 2020: assessment of pharmacists' priorities. Public Health, 155, 69-80. https://doi.org/10.1016/j.puhe.2017.11.010 
Woodard, L.J., McKennon, S., Danielson, J., Knuth, J., \& Odegard, P. (2016). An elective course to train student pharmacists to deliver a community-based group diabetes prevention program. American Journal of Pharmaceutical Education, 80(6). https://doi.org/10.5688/ajpe806106

Zenzano, T., Allan, J. D., Bigley, M. B., Bushardt, R. L., Garr, D. R., Johnson, K., Lang, W., Maeshiro, R., Meyer, S.M., Shannon, S.C., Spolsky, V.W., \& Stanley, J.M. (2011). The Roles of Healthcare Professionals in Implementing Clinical Prevention and Population Health. American Journal of Preventive Medicine, 40(2), 261-267.

https://doi.org/10.1016/j.amepre.2010.10.023 